\title{
Human Capital and
}

\section{Externalities in Cities}

\author{
by \\ Antonio Ciccone \\ Universitat Pompeu Fabra and CEPR \\ and \\ Giovanni Peri \\ Bocconi University and IGIER
}

October 2000 (First Version: January 1999)

\begin{abstract}
We combine growth theory with US Census data on individual schooling and wages to estimate the aggregate return to human capital and human capital externalities in cities. Our estimates imply that a one-year increase in average schooling in cities increases their aggregate labor productivity by 8 to 11 percent. We find no evidence for aggregate human capital externalities in cities however although we use three different approaches. Our main theoretical contribution is to show how human capital externalities can be identified (nonparametrically) even if workers with different levels of human capital are imperfect substitutes in production.

Key Words: Aggregate return to human capital, Human capital externalities, Decreasing returns to human capital, Imperfect substitution, Perfect substitution, Scale Externalities, Cities.
\end{abstract}

JEL Codes: O0, O4, R0, J3.

We thank David Card and UC Data at the University of California, Berkeley for help with the data and Douglas Almond for excellent research assistance. Some of the results in this paper were part of a paper entitled "Capital, Wages, and Growth: Theory and Evidence" by Antonio Ciccone, Giovanni Peri, and Douglas Almond (CEPR Working Paper 2199, May 1999). We thank Adriana Kugler, Claudio Michelacci, and Jonathan Temple for comments. Ciccone thanks the Commission on Research at UC Berkeley and the Spanish Ministry of Education (through a DGICYT grant) for financial support. Corresponding author: Antonio Ciccone, Department of Economics and Business, UPF, Ramon Trias Fargas 25-27, 08005 Barcelona, Spain; Antonio.Ciccone@Econ.Upf.Es. 


\section{Introduction}

Human capital plays a key role in modern growth theory (Lucas (1988), Rebelo (1991), Mankiw, Romer, and Weil (1992)). Empirically, however, the effect of human capital on aggregate labor productivity remains controversial. While some cross-country studies find that the effect is positive and substantial, others report small positive or even negative effects. ${ }^{1}$ We estimate the aggregate return to human capital as well as the strength of human capital externalities in 173 US cities between 1970 and 1990. Our approach combines the human capital framework of modern growth theory with census data on wages and schooling of approximately 4 million individuals. The main advantage of using individual data is that it allows us to identify the strength of human capital externalities. One of the advantages of working with cities instead of countries or regions is that theory suggests that externalities should be stronger at the city-level (Lucas (1988), Glaeser et al. (1992)). Furthermore, the data available for US cities allows us to deal with econometric issues that complicate cross-country studies, like fixed effects, measurement error, and endogeneity of explanatory variables.

Our empirical results indicate that a one-year increase in average schooling in cities raises their aggregate labor productivity by 8 to 11 percent. $^{2}$ We find no evidence for significant aggregate human capital externalities in US cities however. Our preferred estimate of the external effect of a one-year increase in average schooling on average labor productivity and wages is 1 percent with a standard error of 2 percent. This result depends critically on the fact that our theoretical and empirical approach is flexible enough for workers with different levels of human capital to be imperfect substitutes in production. When we impose perfect substitutability, we find statistically significant average schooling externalities between 7 and 11 percent.

\footnotetext{
${ }^{1}$ See Barro (1991), Mankiw, Romer, and Weil (1992), Islam (1995), Temple (1998), Bils and Klenow (2000), and de la Fuente and Domenech (2000).

${ }^{2}$ For comparison, the aggregate return to schooling estimated for OECD countries is below 4 percent (de la Fuente and Domenech (2000)).
} 
Our approach also allows us to estimate the strength of aggregate scale externalities in cities. Following the literature, scale is measured by aggregate employment (Marshall (1890), Sveikauskas (1975), Segal (1976), Henderson (1988)). We find that a 10 percent increase in the aggregate scale of production in US cities has an external effect on wages of 0.7 to 1 percent.

The rest of the paper is organized as follows. Section 2 discusses some of the related literature. Section 3 presents our theoretical framework. Section 4 discusses identification. Section 5 presents the estimating-equations. Section 6 reviews the data and method of estimation. Section 7 presents our results. Section 8 summarizes.

\section{Related Literature}

Closely related to our work is Rauch (1993). He employs US Census data on wages and human capital of individuals in 237 cities in 1980 to estimate externalities in cities using individual wage-regressions. ${ }^{3}$ His results suggest that the external effect of a one-year increase in average schooling in cities on wages of workers in the same city is statistically significant and around 4 percent. Rauch's approach allows for identification of human capital externalities under the assumption that workers with different human capital are perfect substitutes in production. Perfect substitutability simplifies identification in his framework because it implies that the supply of human capital does not affect wages of workers with given human capital if total factor productivity is held constant. Hence, all effects of the supply of human capital on wages of workers with given human capital must work through total factor productivity and can therefore be interpreted as externalities.

Assuming perfect substitutability between workers with different human capital may however erroneously produce the empirical finding of human capital externalities if different workers are in fact imperfect substitutes (Ciccone, Peri, and Almond (1999), Acemoglu and Angrist (2000)). This is because an increase in the supply of human capital will in this case increase wages of some workers even if there are no externalities. We develop three different approaches to estimate human capital externalities when workers with different human capital are imperfect substitutes in production. Our simplest approach looks at how average schooling in cities affects average wages

\footnotetext{
${ }^{3}$ For theoretical work on externalities in cities see Marshall (1890), Jacobs (1969, 1984), Henderson (1988), and Lucas (1988), or more recently, Acemoglu (1996) and Lucas (1999).
} 
holding labor-force composition constant. The other two approaches are more closely related to Rauch as they also use individual wage-regressions.

Rauch (1993) estimates externalities assuming average schooling to be exogenously given. Moretti (1998) accounts for endogeneity of average schooling as well as measurement error and finds large and statistically significant schooling externalities in US cities between 1980 and 1990. Conley, Flier, and Tsang (1999) find significant schooling externalities in Malaysian regions using an instrumental-variables approach. Acemoglu and Angrist (2000) do not find evidence for average schooling externalities at the US state-level; their empirical approach uses instruments for average schooling of states as well as individual schooling. ${ }^{4}$ Our work differs from these papers in that we allow workers with different human capital to be imperfect substitutes in production. ${ }^{5}$ Another difference is that our simplest approach allows us to estimate average schooling externalities without estimating the individual return to schooling and experience. This avoids problems that may arise because individual schooling is endogenous or measured with error (Acemoglu and Angrist (2000)). The fact that our simplest approach sidesteps estimation of individual returns also ensures that empirical findings are not driven by parametric assumptions linking schooling and experience to individual levels of human capital or wages.

Scale externalities in cities are estimated by Sveikauskas (1975), Segal (1976), Moomaw (1981), Henderson (1986), and Rauch (1993). Our contribution is to account for fixed effects, measurement error, and endogeneity of average schooling. ${ }^{6}$

Empirical work relating schooling to aggregate labor productivity across countries is surveyed by de la Fuente and Domenech (2000). They also estimate the increase in average labor productivity associated with a one-year increase in average schooling using improved data for OECD countries. Their results indicate that a oneyear increase in average schooling increases labor productivity by around 4 percent when the induced effect on physical capital accumulation is accounted for.

\footnotetext{
${ }^{4}$ Their results (in their Table 6) show however that instrumenting for individual schooling does not affect estimates of individual returns to schooling or state-level schooling externalities significantly.

${ }^{5}$ Moretti's (1998) theoretical framework allows for imperfect substitutability. However, estimation of the structural equation used to obtain average schooling externalities (in his Table 9) implicitly imposes perfect substitutability. Ciccone (1997) estimates the social return to average schooling in US counties using an approach that allows for imperfect substitutability.

${ }^{6}$ Less closely related is empirical work on how externalities affect employment in cities (instead of labor productivity or wages). Examples include Glaeser et al. (1992) and Henderson et al. (1995) on intra-industry versus inter-industry spillovers and Simon (1999) on human capital externalities.
} 


\section{Human Capital Framework}

To be able to discuss identification of human capital externalities in cities it is necessary to clarify how the supply of human capital affects wages. We analyze this question using the human capital framework of modern growth theory. This framework is flexible enough for workers with different levels of human capital to be perfect or imperfect substitutes in production.

Suppose that each city $c$ at time $t$ produces a quantity $Y_{c t}$ of a composite good according to the aggregate production function

$$
Y_{c t}=\Omega_{c t} G\left(L_{c t}, \Lambda_{c t} H_{c t}\right)
$$

where $\Omega_{c t}$ denotes total factor productivity (TFP), $L_{c t}$ aggregate employment, $\Lambda_{c t}$ an index of exogenous human-capital-augmenting technological change, and $H_{c t}$ the total amount of human capital in the city. $H_{c t}$ is defined as

$$
H_{c t} \equiv \int_{0}^{\infty} H L_{c t}(H) d H
$$

where $L_{c t}(H)$ denotes the number of workers with human capital $H$. The usual assumptions are imposed on $G(L, \Lambda H)$ : continuous differentiability; constant or decreasing marginal returns to human capital, $G_{22}(L, \Lambda H) \leq 0$; and constant returns to scale, $G(\lambda L, \lambda \Lambda H)=\lambda G(L, \Lambda H)$. This last assumption is equivalent to constant returns to labor $L(H)$ for all $H$.

To simplify the exposition we have not included physical capital and land as factors of production in (1). Extending the theoretical and empirical analysis to allow for physical capital is straightforward because it is reasonable to assume that physical capital moves to equalize its rate of return across cities. The main insight of extending the theoretical analysis to allow for land is that the strength of externalities will be identified net of congestion effects. ${ }^{7}$ Both extensions are developed in the appendix.

Suppose that the composite good produced in each city can be sold in a competitive national goods market at a price normalized to unity. The extension of the theoretical and empirical analysis when part of the production of cities is non-tradable can be found in the appendix. ${ }^{8}$ Suppose also that labor markets in cities are perfectly

\footnotetext{
${ }^{7}$ Our theoretical and empirical analysis is consistent with the analysis of wages and rents in Roback (1982) when we include land in production.

${ }^{8}$ The main insight of the theoretical analysis is that our approach will identify externalities in the tradable sector only.
} 
competitive. These assumptions combined with (1) imply that the competitive equilibrium wage-schedule in each city is

$$
w_{c t}(H)=w_{c t}^{L}+w_{c t}^{H} H,
$$

where $w_{c t}(H)$ denotes the wage of workers with human capital $H$, and $w^{L}, w^{H}$ will be referred to as the price of labor and human capital respectively. The price of labor $w_{c t}^{L}$ determines the wage of workers without any human capital in city $c$ at time $t$, while the price of human capital $w_{c t}^{H}$ captures the wage-increase per unit of human capital (the return to human capital). Competitive equilibrium prices of labor and human capital in each city are linked to TFP, the supply of labor, and the supply of human capital in the city by the usual marginal productivity conditions

$$
\begin{gathered}
w_{c t}^{L}=\Omega_{c t} G_{1}\left(1, \Lambda_{c t} h_{c t}\right) \\
w_{c t}^{H}=\Omega_{c t} \Lambda_{c t} G_{2}\left(1, \Lambda_{c t} h_{c t}\right)
\end{gathered}
$$

where $h_{c t} \equiv H_{c t} / L_{c t}$ denotes the supply of human capital relative to labor. Notice that $h_{c t}$ can also be interpreted as the city's average level of human capital at time $t$. The equilibrium average wage of workers in each city is equal to average labor productivity

$$
w_{c t} \equiv \int_{0}^{\infty} w_{c t}(H) l_{c t}(H) d H=\Omega_{c t} G\left(1, \Lambda_{c t} h_{c t}\right)
$$

where $l_{c t}(H) \equiv L_{c t}(H) / L_{c t}$ is the share of workers with human capital $H$ in city $c$.

The specification in (1) allows for constant or decreasing (marginal) returns to human capital. Constant (marginal) returns $G_{22}\left(1, \Lambda_{c t} h_{c t}\right)=0$ imply that the aggregate production function simplifies to

$$
Y_{c t}=\Omega_{c t}\left(A L_{c t}+\Lambda_{c t} B H_{c t}\right)
$$

where $A, B \geq 0$ are constants; hence, workers with different human capital are perfect substitutes. It is straightforward to show that the reverse also holds, i.e. perfect substitutability between workers with different human capital implies constant returns to human capital. Decreasing (marginal) returns to human capital $G_{22}\left(1, \Lambda_{c t} h_{c t}\right)<0$, on the other hand, imply that workers with different human capital are imperfect substitutes. Hence, wages of workers with low human capital relative to workers with high human capital depend on the supply of workers with low and high human capital in the city. To 
see this in a simple way suppose that the supply of workers with low human capital $H_{l}$ in a city decreases while the supply of workers with high human capital $H_{h}\left(H_{h}>H_{l}\right)$ increases so as to keep the total number of workers constant. What is the effect on relative wages of low human capital workers $w\left(H_{l}\right) / w\left(H_{h}\right)$ ? It is shown in the appendix that the effect of the change in supply on relative wages is proportional to $-G_{22}\left(1, \Lambda_{c t} h_{c t}\right)\left(H_{h}-H_{l}\right)^{2}$. Hence, relative wages of low human capital workers increase if and only if there are decreasing returns to human capital. The increase in relative wages is smaller if the two levels of human capital are similar. This is because the closer the levels of human capital of the two "types" of workers, the better they substitute for one another.

So far the level of TFP in cities has been taken as exogenous. We now allow for human capital externalities in cities by following Lucas (1988) in linking the level of TFP to the average level of human capital. The specification for TFP in each city is

$$
\Omega_{c t}=\Phi_{c t} h_{c t}^{\theta} L_{c t}^{\delta}
$$

with $\delta, \theta \geq 0$, where $\Phi_{c t}$ stands for exogenous factors that affect TFP across cities. The strength of human capital externalities is captured by the elasticity of TFP with respect to average human capital $\theta$. The specification in (8) also allows for scale externalities where scale is measured by aggregate employment in cities. Scale externalities in cities are emphasized in Marshall (1890) and Henderson (1988), and estimated in Sveikauskas (1975), Moomaw (1981), Henderson (1986, 1988), and Rauch (1993) for example.

The specification in (8) captures technological externalities. In the appendix we discuss how our analysis can be applied to models with an endogenous variety of nontradable goods produced with increasing returns and "pecuniary" instead of technological externalities (Krugman (1992)).

Constant returns to human capital given TFP imply that the equilibrium wageschedule simplifies to $w_{c t}(H)=\Omega_{c t}\left(A+\Lambda_{c t} B H\right)$. This can be seen by combining (3)-(5) and (7). Wages of workers with a given level of human capital will therefore be independent of the average level of human capital in the city if TFP is held constant. Hence, all effects of the average level of human capital on the equilibrium wageschedule must arise through TFP and can be interpreted as externalities. However, this is no longer the case when the aggregate production function is subject to decreasing returns to human capital given TFP. An increase in the average level of human capital 
holding TFP constant will in this case raise wages of some "types" of workers and lower wages of other "types." To see this notice that $G_{22}\left(1, \Lambda_{c t} h_{c t}\right)<0$ implies that the price of human capital decreases if the average level of human capital in the city increases and TFP is held constant. Furthermore, decreasing returns to human capital given TFP imply that labor and human capital are Edgeworth complements in (1) $G_{12}\left(1, \Lambda_{c t} h_{c t}\right)>0$. ${ }^{9}$ An increase in the average level of human capital holding TFP constant will therefore increase the price of labor. Combining the increase in the price of labor and the decrease in the price of human capital with (3) yields that wages of workers with low (high) human capital increase (decrease) if the average level of human capital in the city increases and TFP is held constant. We will refer to all effects of average human capital in a city on wages when holding TFP constant as supply effects.

Workers must be indifferent between living in different cities in general equilibrium. Formally this implies that equilibrium wage-schedules across cities must satisfy $U^{i}\left(w_{c t}(H), z_{c t}, t\right)=U^{i}\left(w_{\mathrm{k} t}(H), z_{\mathrm{k} t}, t\right)$ for $i \in I$, where $z_{c t}, z_{\mathrm{k} t}$ denote vectors of all characteristics of cities $c, \kappa$ that are relevant for utility $U^{i}$ of workers of type $i ; i$ captures that workers may differ in preferences. Examples of city-characteristics that may be relevant to workers are the cost of housing, the quality of the public school system, local tax-rates, the degree of air pollution, the crime rate, climate, outdoor recreational opportunities, proximity to family or friends, and the variety or quality of restaurants or sports teams.

\section{Identification}

We now use the human capital framework to discuss identification of scale and human capital externalities in cities. The simplest of our three approaches to identify human capital externalities looks at how average levels of human capital in cities affect average wages holding labor-force composition constant. The other two approaches require data on prices of human capital and labor as well as average levels of human capital across cities for different years. We start with identification of human capital and scale externalities using the approach based on average wages.

\footnotetext{
${ }^{9}$ To see this notice that constant returns to scale of the production function in (1) given TFP implies $G_{1}(1, \Lambda h)+G_{2}(1, \Lambda h) \Lambda h=G(1, \Lambda h)$ for all $h$. Differentiating with respect to average human capital yields $G_{12}(1, \Lambda h)=-G_{22}(1, \Lambda h) \Lambda h$.
} 


\subsection{Identification Using Average Wages}

The strength of scale externalities $\delta$ can be identified directly from the partial elasticity of average wages with respect to aggregate employment in cities. To see this notice that (6) and (8) imply

$$
\frac{\partial \ln w_{c t}}{\partial \ln L_{c t}}=\delta .
$$

Combining (6) and (8) also yields that the partial elasticity of average wages with respect to average human capital is equal to

$$
\varepsilon_{c t} \equiv \frac{\partial \ln w_{c t}}{\partial \ln h_{c t}}=\theta+\frac{\partial \ln G\left(1, \Lambda_{c t} h_{c t}\right)}{\partial \ln h_{c t}} .
$$

The first term on the right-hand side captures human capital externalities and the second term the effect of human capital on average wages when holding TFP constant. An increase in average human capital will in general increase average wages even if TFP does not change. Hence, knowledge of the partial elasticity of average wages with respect to average human capital $\varepsilon_{c t}$ is not sufficient to identify the strength of human capital externalities $\theta$.

The strength of human capital externalities $\theta$ can however be identified directly from the effect of average human capital on average wages holding labor-force composition constant. To see this define the elasticities of the price of labor and human capital in cities with respect to average human capital as $\varepsilon_{c t}^{L} \equiv \partial \ln w_{c t}^{L} / \partial \ln h_{c t}$ and $\varepsilon_{c t}^{H} \equiv \partial \ln w_{c t}^{H} / \partial \ln h_{c t}$ respectively. Furthermore, denote the share of human capital in average wages by $\lambda_{c t} \equiv w_{c t}^{H} h_{c t} / w_{c t}$. With this notation (3)-(8) imply

$$
\begin{aligned}
\left.\varepsilon_{c t}^{F} \equiv \frac{\partial w_{c t}}{\partial h_{c t}} \frac{h_{c t}}{w_{c t}}\right|_{\text {Holding } l_{c t}(H), \forall H \text { constant }} & \int_{0}^{\infty} l_{c t}(H)\left(\lambda_{c t} \varepsilon_{c t}^{H}\left(H / h_{c t}\right)+\left(1-\lambda_{c t}\right) \varepsilon_{c t}^{L}\right) d H \\
& =\lambda_{c t} \varepsilon_{c t}^{H}+\left(1-\lambda_{c t}\right) \varepsilon_{c t}^{L} \\
& =\theta
\end{aligned}
$$

The last equality follows from constant returns to scale to labor $L(H)$ for all $H$ given TFP of the aggregate production function. ${ }^{10}$ To understand (11) it is useful to

\footnotetext{
${ }^{10}$ The equality is very closely related to the dual approach to TFP accounting. To see this suppose $\Lambda_{c t} \equiv 1$ and denote the unit-cost function associated with production of $Y$ in (1) with $\Omega^{-1} c\left(w^{L}, w^{H}\right)$. Perfect competition and normalization of the composite-good price to unity imply that in equilibrium $\Omega\left(h_{c t}, L_{c t}, t\right)^{-1} c\left(w^{L}\left(h_{c t}, L_{c t}, t\right), w^{H}\left(h_{c t}, L_{c t}, t\right)\right) \equiv 1$ where $w^{X}(\bullet)$ denotes equilibrium prices as a function of
} 
distinguish two cases. First suppose that the aggregate production function is subject to constant returns to human capital given TFP. Wages of workers with a given level of human capital will in this case be independent of the average level of human capital in the city if TFP is held constant. Hence, all effects of average human capital on average wages holding labor-force composition constant can be interpreted as externalities. Now assume instead that the aggregate production function is subject to decreasing returns to human capital given TFP (workers with different human capital are imperfect substitutes). Suppose also that the average level of human capital in a city increases but that TFP is held constant. In this case wages of some "types" of workers will increase and wages of others "types" will decrease due to supply effects. According to (11), these supply effects will cancel however when we consider average wages holding laborforce composition constant. To understand this intuitively assume $\Lambda_{c t} \equiv \Omega_{c t} \equiv 1$ in (1) and that the city considered experiences an inflow of workers with high human capital. In particular, suppose that the shares of workers with different human capital go from $\{l(H): H \geq 0\}$ to $\{l *(H): H \geq 0\}$ and that the implied increase in average human capital is $\Delta h$. Using that labor and human capital are the only factors of production and that wages are linear in human capital yields that the increase in the average wage holding composition constant is $\int_{0}^{\infty}\left(w^{L}(h+\Delta h)+w^{H}(h+\Delta h) H\right) l(H) d H-G(1, h)$, where $w^{X}(h+\Delta h)$ denotes equilibrium prices of labor and human capital as a function of average human capital in the city. This increase can be rewritten as the increase in the average wage minus the increase in the average wage due to the change in labor-force composition $G(1, h+\Delta h)-G(1, h)-w^{H}(h+\Delta h) \Delta h$. The average increase in the average wage holding composition constant is therefore $(G(1, h+\Delta h)-G(1, h)) / \Delta h-w^{H}(h+\Delta h)$. This increase converges to $G_{2}(1, h)-w^{H}(h)$, which is zero in equilibrium, as the increase in average human capital becomes smaller. Hence, the average wage holding composition constant does not change with a small increase in average human capital because in equilibrium the increase in the average wage goes to the additional human capital. Any net effect of the average level of human capital in a city on average wages

$\left(h_{c t}, L_{c t}, t\right)$ and $\Omega(\bullet)$ captures (8). Totally differentiating with respect to time using Shephard's Lemma yields the dual approach to TFP accounting $d \ln \Omega_{c t} / d t=\lambda_{c t}\left(d \ln w_{c t}^{H} / d t\right)+$ $\left(1-\lambda_{c t}\right)\left(d \ln w_{c t}^{L} / d t\right)$ with the usual interpretation. Partially differentiating with respect to human capital yields the last equality in (11) $\partial \ln \Omega_{c t} / \partial \ln h_{c t}=\lambda_{c t}\left(\partial \ln w_{c t}^{H} / \partial \ln h_{c t}\right)+\left(1-\lambda_{c t}\right)\left(\partial \ln w_{c t}^{L} / \partial \ln h_{c t}\right)$. 
holding labor-force composition constant must therefore work through TFP and can be interpreted as human capital externalities. Notice that the approach in (11) works for any aggregate production function within the human capital framework.

To see how externalities to average years of schooling in cities can be identified suppose that a one-year increase in average schooling raises average human capital by $f$ percent. Then the strength of externalities to average schooling $f \theta$ is equal to the percentage-increase in average wages holding labor-force composition constant due to a one-year increase in average schooling.

The effect of aggregate employment on average wages holding labor-force composition constant is

$$
\left.\frac{\partial w_{c t}}{\partial L_{c t}} \frac{L_{c t}}{w_{c t}}\right|_{\text {Holding } l_{c t}(H), \forall H \text { constant }}=\delta .
$$

Scale externalities can therefore be identified either using average wages in (9) or average wages holding labor-force composition constant in (12).

\subsection{Identification Using Prices of Human Capital and Labor}

In addition to the approach based on average wages, there are two other approaches to identify human capital externalities without any prior knowledge on whether returns to human capital given TFP are constant or decreasing. Both require data on prices of human capital $w_{c t}^{H}$ and labor $w_{c t}^{L}$ as well as average levels of human capital $h_{c t}$ across cities for different years.

We first deal with identification of human capital externalities in the special case of constant returns to human capital given TFP. This special case is useful as a benchmark and because it yields the approach to identification in Rauch (1993) and Acemoglu and Angrist (2000). Then we discuss the two approaches to identify human capital externalities when decreasing returns to human capital are a possibility.

\section{Assuming Constant Returns to Human Capital (Perfect Substitutability)}

Assume constant returns to human capital given TFP $G_{22}=0$ and also that human capital is essential in production. Then the aggregate production function simplifies to (7) with $A=0$, and the equilibrium price of labor in (4) is therefore $w_{c t}^{L}=0$. Hence, the equilibrium wage-schedule in (3) becomes $w_{c t}(H)=w_{c t}^{H} H$ where 


$$
w_{c t}^{H}=\Phi_{c t} \Lambda_{c t} B h_{c t}^{\theta} L_{c t}^{\delta} .
$$

(13) combines (5), (7), and (8). The strength of human capital externalities $\theta$ can therefore be identified directly from the elasticity of the price of human capital with respect to average human capital

$$
\varepsilon_{c t}^{H}=\frac{\partial \ln w_{c t}^{H}}{\partial \ln h_{c t}}=\theta .
$$

The reason why it is straightforward to identify human capital externalities in this case is simple. $G_{22}=0$ implies that the supply of workers with different levels of human capital in cities will not affect wages of workers with given human capital if TFP is held constant. All effects of the average level of human capital on wages of workers with given characteristics (and hence on the price of human capital) can therefore be interpreted as externalities.

To identify externalities to average years of schooling in cities $S_{c t}$ suppose again that a one-year increase in average schooling raises average human capital by $f$ percent. Then externalities to average schooling in cities are given by $f \theta=\partial \ln w_{c t}^{H} / \partial S_{c t}$.

If we maintain constant returns to human capital given TFP but relax the assumption that human capital is essential in production then (7) and (8) imply $w_{c t}^{L}=A \Omega_{c t}=A \Phi_{c t} h_{c t}^{\theta} \delta_{c t}^{\delta}>0$ and $\varepsilon_{c t}^{L}=\partial \ln w_{c t}^{L} / \partial \ln h_{c t}=\theta$. Hence, (14) yields $\varepsilon_{c t}^{L}=\varepsilon_{c t}^{H}=\theta$. The elasticities of the price of labor and human capital with respect to average human capital are therefore identical and equal to the strength of human capital externalities in this case.

\section{Allowing for Decreasing Returns to Human Capital}

Identification of human capital externalities using prices of human capital and labor is less straightforward when decreasing returns to human capital are a possibility. This is because the supply of workers with different human capital in the city may in this case affect wages of workers with given human capital even if TFP does not change. Hence, it is no longer possible to ascribe all effects of the average level of human capital on the price of human capital to externalities. This can be seen formally by substituting (8) in (5) and partially differentiating with respect to average human capital

$$
\varepsilon_{c t}^{H}=\frac{\partial \ln w_{c t}^{H}}{\partial \ln h_{c t}}=\theta+\frac{G_{22}\left(1, \Lambda_{c t} h_{c t}\right) \Lambda_{c t} h_{c t}}{G_{2}\left(1, h_{c t}\right)} .
$$


Thus, the elasticity of the price of human capital with respect to average human capital underestimates $\theta$ when there are decreasing returns to human capital given TFP. The elasticity of the price of labor with respect to average human capital, on the other hand, overestimates $\theta$ when there are decreasing returns to human capital given TFP. This can be seen formally by substituting (8) into (4) and partially differentiating with respect to average human capital

$$
\varepsilon_{c t}^{L}=\frac{\partial \ln w_{c t}^{L}}{\partial \ln h_{c t}}=\theta+\frac{G_{12}\left(1, \Lambda_{c t} h_{c t}\right) \Lambda_{c t} h_{c t}}{G_{1}\left(1, h_{c t}\right)} .
$$

It has already been said that decreasing returns to human capital given TFP implies $G_{12}\left(1, \Lambda_{c t} h_{c t}\right)>0$. Decreasing returns to human capital therefore yields

$$
\varepsilon_{c t}^{H}<\theta<\varepsilon_{c t}^{L} .
$$

and hence that $\varepsilon_{c t}^{H}\left(\varepsilon_{c t}^{L}\right)$ underestimates (overestimates) the strength of human capital externalities in cities. To identify $\theta$ it is necessary to combine $\varepsilon_{c t}^{H}$ and $\varepsilon_{c t}^{L}$ with the share of human capital in wages $\lambda_{c t}=w_{c t}^{H} h_{c t} / w_{c t}$ using (11)

$$
\lambda_{c t} \varepsilon_{c t}^{H}+\left(1-\lambda_{c t}\right) \varepsilon_{c t}^{L}=\theta
$$

This equation holds whether returns to human capital given TFP are decreasing or constant.

Identification of the strength of human capital externalities using (18) requires estimates of the effect of an increase in the average level of human capital on the prices of labor and human capital for each city and time-period. In practice however it is only possible to identify average effects using either data across cities for a given time-period or data over different time-periods for a given city. Our data allows us to estimate the average effect of an increase in average human capital on the prices of labor and human capital across cities for a given time-period. To see how these estimates can be used to infer $\theta$ suppose that the share of human capital in wages $\lambda_{c t}$ and the difference between the elasticity of the price of human capital and labor with respect to average human capital $\varepsilon_{c t}^{L}-\varepsilon_{c t}^{H}$ are independently distributed across cities; for example, this condition holds if the aggregate production function is of the constant-elasticity-of-substitution type. In this case taking the expectation of (18) across cities yields

$$
\lambda_{t} \varepsilon_{t}^{H}+\left(1-\lambda_{t}\right) \varepsilon_{t}^{L}=\theta
$$


where $\varepsilon_{t}^{H} \equiv E_{t} \varepsilon_{c t}^{H}, \varepsilon_{t}^{L} \equiv E_{t} \varepsilon_{c t}^{L}$, and $\lambda_{t} \equiv E_{t} \lambda_{c t}$. The strength of human capital externalities $\theta$ can therefore be identified from the "average" elasticities $\varepsilon_{t}^{H}, \varepsilon_{t}^{L}$, and the "average" share of human capital in wages $\lambda_{t}$. This approach works whether returns to human capital given TFP are constant or decreasing.

The second approach to identify $\theta$ using prices of human capital and labor together with average levels of human capital relies on a well-known result. Under perfect competition the elasticity of output with respect to a production factor is equal to the income share of that factor if there are no externalities. Hence, we can estimate the strength of human capital externalities by comparing the share of human capital in wages to the elasticity of average wages with respect to average human capital. To see this formally notice that competitive labor markets imply that the elasticity of average wages with respect to average human capital holding TFP constant is equal to the share of human capital in wages

$$
\frac{\partial \ln G\left(1, h_{c t}\right)}{\partial \ln h_{c t}}=\frac{w_{c t}^{H} h_{c t}}{w_{c t}}=\lambda_{c t},
$$

where we made use of (5) and (6). Rearranging (10) and making use of (20) yields that human capital externalities can be identified as the difference between the partial elasticity of average wages with respect to average human capital and the share of human capital in wages

where $\varepsilon_{t} \equiv E_{t} \varepsilon_{c t}$.

$$
\theta=\varepsilon_{t}-\lambda_{t}
$$

To identify externalities to average years of schooling in cities it is necessary to combine the strength of human capital externalities $\theta$ obtained using (19) or (21) with the percentage-increase in average human capital due to a one-year increase in average schooling $f \equiv \partial \ln h_{c t} / \partial S_{c t}$.

\section{Estimation}

We now discuss empirical implementation of our three approaches to identify human capital externalities in cities. The discussion starts with the approach based on average wages. Then we turn to the two approaches that require prices of human capital and labor as well as average human capital across cities for different years. We also discuss estimation of scale externalities and the aggregate return to human capital. 


\subsection{Estimation Using Average Wages}

We start with estimation of scale externalities and the aggregate return to average schooling and experience in cities. Then we turn to estimation of externalities to average schooling and experience.

Consider a log-linear approximation of (6) and (8) around given values for the average level of human capital and the index of exogenous human-capital-augmenting technological change. This yields that $\ln w_{c t}=a+\ln \Phi_{c t}+(\varepsilon-\theta) \ln \Lambda_{c t}+\delta \ln L_{c t}+\varepsilon \ln h_{c t}$ where $\varepsilon$ is the elasticity of average wages with respect to average human capital and $a$ is some constant. Taking differences of this last equation over time and approximating the log-change of the average level of human capital in cities with the change of average years of schooling $\Delta S_{c t}$ and experience $\Delta E_{c t}$ yields the estimating-equation

$$
\Delta \ln w_{c t}=\text { OtherControls }+\delta \Delta \ln L_{c t}+\alpha^{A} \Delta S_{c t}+\gamma^{A} \Delta E_{c t}+v_{c t}
$$

where $\Delta x_{c t}=x_{c \tau}-x_{c t}$. "OtherControls" stands for all other control variables used in the regression and $v_{c t}=\Delta \ln \Phi_{c t}+(\varepsilon-\theta) \Delta \ln \Lambda_{c t}$ is a weighted average of (unobservable) changes of exogenous technology. The parameters $\alpha^{A}$ and $\gamma^{A}$ measure the aggregate return to schooling and experience in cities, i.e. the percentage-increase in average wages associated with a one-year increase in average schooling and experience in cities. Notice that we have eliminated permanent differences in exogenous technology across cities (city-specific fixed effects) from the estimating-equation in (22) by considering log-differences over time.

We can now assess how much of the aggregate return to schooling and experience captured by $\alpha^{A}$ and $\gamma^{A}$ is due to externalities. According to (11), this requires estimating the effect of average schooling and experience on average wages holding labor-force composition constant. Denote the average wage of workers with years of schooling $S$, experience $E$, and other characteristics $X$ (e.g. gender, race, marital status) in city $c$ at time $t$ with $w_{c t}(S, E ; X)$. Then we can define average wages in cities holding labor-force composition constant over time as

$$
w_{c t}^{F} \equiv \sum_{S, E, X} w_{c t}(S, E ; X) l_{c}(S, E ; X)
$$

where $l_{c}(S, E ; X)$ denotes the share of workers with characteristics $(S, E ; X)$ in city $c$ in the base year. According to (11), externalities associated with average years of schooling and experience in cities can be estimated using 


$$
\Delta \ln w_{c t}^{F}=\text { OtherControls }+\delta \Delta \ln L_{c t}+\alpha^{E} \Delta S_{c t}+\gamma^{E} \Delta E_{c t}+v_{c t}^{F},
$$

where $\alpha^{E}$ and $\gamma^{E}$ measure the strength of externalities to average schooling and experience in cities. The estimating-equation also uses that, according to (12), the strength of scale externalities can be estimated using average wages holding labor-force composition constant. City-specific fixed effects have again been eliminated from the estimating-equation by considering log-differences over time.

We estimate (24) using two different samples. A sample that includes all workers we have data for and a restricted sample including only workers who are white and male. Working with the more restricted sample eliminates problems that may arise because of time-varying race and gender wage-differentials.

Our data also allow for a second approach to deal with time-varying wagedifferentials associated with gender and race as well as marital status. This approach involves estimating city-year specific average wages of workers with schooling $S$ and experience $E$ adjusted by gender, race, and marital status $\omega_{c t}(S, E)$. To do so we use the sample of workers with levels of schooling $S$ and experience $E$ to estimate

$$
\ln w_{c t}\left(S, E ; X_{i c t}\right)=\ln \omega_{c t}(S, E)+\sum_{j \in J} d_{j r t}(S, E) X_{j i c t}+u_{i c t}
$$

where $\left\{X_{j}: j \in J\right\}$ denotes dummies for gender, race, and marital status, and $d_{j r t}(S, E)$ captures the effect of $X_{j}$ on the wage of workers with schooling $S$ and experience $E$ in region $r$ at time $t$. Subscripts ict indicate individual $i$ in city $c$ at time $t$. Notice that we allow the effect of gender, race, and marital status on wages to change over time and across regions (our empirical work partitions the US into 5 regions). Furthermore, we also allow these effects to differ according to the level of schooling and experience of workers. The regression in (25) will be set up so that the constant corresponds to white married males. Estimates of adjusted city-year specific average wages of workers with schooling $S$ and experience $E$ can be used to calculate city-year specific adjusted average wages holding labor-force composition constant

$$
\hat{w}_{c t}^{F A} \equiv \sum_{S, E} \hat{\omega}_{c t}(S, E) l_{c}(S, E)
$$

Hats denote values estimated using (25). City-year specific adjusted average wages holding labor-force composition constant $\hat{w}_{c t}^{F A}$ will be used as the left-hand side variable in (24) to obtain a cleaner estimate of scale and human capital externalities. 


\subsection{Estimation Using Individual-Level Wage-Regressions}

We now turn to estimation of human capital externalities in cities using the two approaches that require prices of human capital $w_{c t}^{H}$ and labor $w_{c t}^{L}$ as well as average levels of human capital $h_{c t}$ across cities for different years. These prices and average human capital will be estimated using individual-level wage-regressions. Furthermore, we also discuss estimation of scale externalities and the aggregate return to human capital.

We first deal with the very special case where the aggregate production function is subject to constant returns to human capital given TFP and human capital is essential in production. This special case turns out to be useful as a starting point and for comparisons. Furthermore, it yields the Mincerian wage-regression framework used to estimate average schooling externalities in Rauch (1993) and Acemoglu and Angrist (2000). Then we turn to estimation in the general case where we allow for decreasing returns to human capital.

\section{Estimation Using Mincerian Wage-Regressions}

Suppose that the aggregate production function in (1) is subject to constant returns to human capital given TFP and that human capital is essential in production. In this case (14) implies that the strength of human capital externalities $\theta$ can be estimated directly from the elasticity of the price of human capital with respect to average human capital. We now show that city-year specific prices of human capital $w_{c t}^{H}$ and average levels of human capital $h_{c t}$ can be estimated using Mincerian wage-regressions. We also discuss estimation of aggregate returns to scale to human capital, aggregate and external returns to average schooling, and scale externalities in cities.

Constant returns to human capital given TFP and essential human capital imply $w_{c t}^{L}=0$ and hence that the equilibrium wage-schedule simplifies to $w_{c t}(H)=w_{c t}^{H} H$. Suppose that individual levels of human capital $H$ depend on individual schooling $S$ and experience $E$ according to

$$
H_{t}(S, E) \equiv \exp \left(b_{t} S+c_{t} E-e_{t} E^{2}\right) .^{11}
$$

This specification is chosen because the equilibrium wage-schedule becomes $\ln w_{c t}\left(H_{t}(S, E)\right)=\ln w_{c t}^{H} H_{t}(S, E)=\ln w_{c t}^{H}+b_{t} S+c_{t} E-e_{t} E^{2}$. Hence, the equilibrium wageschedule can be estimated using Mincerian wage-regressions (Mincer (1974)). We

\footnotetext{
${ }^{11}$ The human capital of workers with no schooling and experience in (27) is normalized to unity. This simplifies the exposition without affecting the theoretical or empirical analysis.
} 
estimate Mincerian wage-regressions that control not only for individual schooling and experience but also for gender, race, and marital status

$$
\begin{aligned}
\ln w_{i c t} & =\ln w_{c t}^{H} H_{t}\left(S_{i c t}, E_{i c t}\right)+\sum_{j \in J} d_{j r t} X_{j i c t}+u_{i c t} \\
& =\ln w_{c t}^{H}+b_{t} S_{i c t}+c_{t} E_{i c t}-e_{t} E_{i c t}^{2}+\sum_{j \in J} d_{j r t} X_{j i c t}+u_{i c t}
\end{aligned},
$$

where $\left\{X_{j}: j \in J\right\}$ denotes dummies for gender, race, and marital status, and $d_{j r t}$ denotes the region-time specific effect of these dummies on individual wages; $u_{i c t}$ captures unobservable factors that affect individual wages. Empirical implementation of (28) for different years yields estimates of city-year specific prices of human capital $\hat{w}_{c t}^{H}$ as well as the function $\hat{H}_{t}(S, E)$ linking individual levels of schooling and experience to human capital. Hats denote estimates obtained using (28). City-year specific average levels of human capital can be estimated by aggregation

$$
\hat{h}_{c t}=\sum_{S, E} l_{c t}(S, E) \hat{H}_{t}(S, E)
$$

where $l_{c t}(S, E)$ is the share of workers with schooling $S$ and experience $E$ in city $c$ at time $t$. Average wages adjusted for gender, race, and marital status implied by the Mincerian approach are $\hat{w}_{c t}=\hat{w}_{c t}^{H} \hat{h}_{c t}$.

It is convenient to start with estimation of scale externalities $\delta$. According to (9), the strength of scale externalities is given by the partial elasticity of average wages with respect to aggregate employment. Hence, $\delta$, as well as the partial elasticity of average wages with respect to average human capital $\varepsilon$, can be estimated using

$$
\Delta \ln \hat{w}_{c t}=\text { OtherControls }+\delta \Delta \ln L_{c t}+\varepsilon \Delta \ln \hat{h}_{c t}+u_{c t},
$$

where $u_{c t}$ captures the (unobservable) change of exogenous technology. Notice that $\varepsilon$ is the strength of aggregate returns to scale to human capital and hence that $\varepsilon>1 \quad(\varepsilon<1)$ implies increasing (decreasing) aggregate returns to scale to human capital.

To see how much of the strength of aggregate returns to scale to human capital is due to externalities, we need to estimate $\theta$. According to (14), $\theta$ is equal to the partial elasticity of the price of human capital $w_{c t}^{H}$ with respect to average human capital $h_{c t}$. Hence, $\theta=\varepsilon^{H}$ can be estimated using

$$
\Delta \ln \hat{w}_{c t}^{H}=\text { Employment\&OtherControls }+\varepsilon^{H} \Delta \ln \hat{h}_{c t}+u_{c t}^{H},
$$


where $u_{c t}^{H}$ captures the (unobservable) change of exogenous technology. "Employment\&OtherControls" stands for all other control variables used, including the log-change of aggregate employment in cities during the time-period.

For comparisons with the approach based on average wages only, we also estimate the aggregate and external return to average schooling and experience in cities implied by the Mincerian approach. The aggregate effect of average schooling and experience on average wages can be estimated using

$$
\Delta \ln \hat{w}_{c t}=\text { Employment\&OtherControls }+\alpha^{A} \Delta S_{c t}+\gamma^{A} \Delta E_{c t}+v_{c t}
$$

where $\Delta \ln \hat{w}_{c t}=\Delta \ln \hat{w}_{c t}^{H} \hat{h}_{c t}$. Externalities to average schooling and experience in cities, on the other hand, can be estimated by looking at the effect of average schooling and experience on the price of human capital using

$$
\Delta \ln \hat{w}_{c t}^{H}=\text { Employment\&OtherControls }+\alpha^{E} \Delta S_{c t}+\gamma^{E} \Delta E_{c t}+v_{c t}^{H} .
$$

\section{Estimation Allowing for Decreasing Returns to Human Capital}

Decreasing returns to human capital given TFP imply that the equilibrium price of labor is strictly positive. Hence, it is necessary to relax the assumption $w_{c t}^{L}=0$ implicit in the Mincerian wage-regression in (28). Using (3) yields the following individual-level estimating-equation for the case of decreasing returns to human capital

$$
\ln w_{i c t}=\ln \left(w_{c t}^{L}+w_{c t}^{H} H_{t}\left(S_{i c t}, E_{i c t}\right)\right)+\sum_{j \in J} d_{j r t} X_{j i c t}+u_{i c t}
$$

where $H_{t}(S, E)$ is specified in (27). The Mincerian wage-regression corresponds to the special case where $w_{c t}^{L}=0$.

Estimation of (34) yields city-year specific prices of labor $\hat{w}_{c t}^{L}$ and human capital $\hat{w}_{c t}^{H}$ as well as the function $\hat{H}_{t}(S, E)$ linking individual schooling and experience to individual human capital. Hats denote estimates obtained using (34). Aggregating individual levels of human capital using (29) yields estimates of city-year specific average human capital. Average wages adjusted for gender, race, and marital status are estimated as $\hat{w}_{c t}=\hat{w}_{c t}^{L}+\hat{w}_{c t}^{H} \hat{h}_{c t}$.

The strength of scale externalities $\delta$, and the partial elasticity of average wages with respect to average human capital $\varepsilon$, can now be estimated using

$$
\Delta \ln \hat{w}_{c t}=\text { OtherControls }+\delta \Delta \ln L_{c t}+\varepsilon \Delta \ln \hat{h}_{c t}+u_{c t} ;
$$


$\varepsilon>1 \quad(\varepsilon<1)$ corresponds to increasing (decreasing) aggregate returns to scale to human capital.

City-year specific prices of labor and human capital can also be used to estimate the partial elasticities of the price of human capital and labor with respect to average human capital $\varepsilon^{H}, \varepsilon^{L}$ with the following estimating-equations

$$
\begin{aligned}
& \Delta \ln \hat{w}_{c t}^{H}=\text { Employment\&OtherControls }+\varepsilon^{H} \Delta \ln \hat{h}_{c t}+u_{c t}^{H} \\
& \Delta \ln \hat{w}_{c t}^{L}=\text { Employment\&OtherControls }+\varepsilon^{L} \Delta \ln \hat{h}_{c t}+u_{c t}^{L} .
\end{aligned}
$$

Combining city-year specific average human capital with prices of labor and human capital yields estimates of city-year specific shares of human capital in wages

$$
\hat{\lambda}_{c t}=\frac{\hat{w}_{c t}^{H} \hat{h}_{c t}}{\hat{w}_{c t}^{L}+\hat{w}_{c t}^{H} \hat{h}_{c t}} .
$$

A consistent point estimate and standard error for $\theta$ can be obtained in the following way. We first determine the asymptotic distribution of the estimators for $\varepsilon^{H}, \varepsilon^{L}$ in (36) and (37). This distribution is combined with estimates of the share of human capital in wages to simulate the asymptotic distribution of $\theta$ using (19). The average value and standard deviation of the simulated distribution are then used as point estimate and standard error for $\theta$. Details are in the appendix.

Our second approach to estimate $\theta$ using individual-level wage-regressions relies on (21). The resulting point estimate is $\hat{\theta}=\hat{\varepsilon}-\hat{\lambda}$ with $\hat{\varepsilon}$ the elasticity of average wages with respect to average human capital estimated using (35) for some time-period and $\hat{\lambda}$ the share of human capital in wages in (38) averaged over the same time-period.

The strength of externalities to average schooling cannot be estimated directly as in the Mincerian case. Instead, average schooling externalities must be estimated by combining estimates of $\theta$ with estimates of the effect of average schooling on average human capital $f=\partial \ln h / \partial S$ obtained using

$$
\Delta \ln \hat{h}_{c t}=\text { Constant }+f \Delta S_{c t}+g \Delta E_{c t} .
$$

The resulting point-estimate of externalities to average years of schooling is $\hat{f} \hat{\theta}$. 
For comparison with the approach based on average wages only, it is useful to estimate the aggregate return to average schooling in cities implied by individual-level wage-regressions that allow for decreasing returns to human capital. This is done using

$$
\Delta \ln \hat{w}_{c t}=\text { Employment\&OtherControls }+\alpha^{A} \Delta S_{c t}+\gamma^{A} \Delta E_{c t}+v_{c t}
$$

where $\Delta \ln \hat{w}_{c t}=\Delta \ln \left(\hat{w}_{c t}^{L}+\hat{w}_{c t}^{H} \hat{h}_{c t}\right)$.

\section{Data and Method of Estimation}

We use data on approximately 4 million individuals in 173 cities in 1970, 1980, and 1990. The data comes from the public use micro samples (PUMS) of the US Census (US Bureau of Census (1970, 1980, 1990)). Individual wages are measured as hourly wages. Individual experience is measured as potential experience, i.e. age minus years of schooling minus 6 . When we implement (25), we partition potential experience in 4 intervals and individual schooling in 7 intervals, which yields a total of 28 schoolingexperience combinations $(S, E)$. When we implement the individual-level wageregressions in (28) and (34), we use years of potential experience and 11 levels for individual schooling. Details on the data and on the construction of variables can be found in the appendix. Our definition of cities corresponds, with some exceptions, to the US Bureau of Census definition of standard metropolitan statistical areas (SMSAs) in 1990 and is explained in detail in the appendix. Aggregate employment in cities in 1970, 1980, and 1990 is constructed by adding employment of all counties that were contained in the city in 1990. County-employment in 1970, 1980, and 1990 is the number of people with part-time or full-time jobs and comes from the U.S. Department of Commerce (US Department of Commerce (1992)). We only consider employment in the private sector and exclude agriculture and mining. Average years of schooling and experience in cities is obtained by aggregating years of schooling and potential experience of individuals in each city. Average schooling across cities rose by 1.2 years during the 20year period 1970-1990; the standard deviation of the increase in average schooling across cities was 0.56 and the maximal increase 2.1 years. The corresponding figures are $0.96,0.26$, and 1.6 for the 10-year period 1970-1980, and $0.22,0.28$, and 0.87 for 1980-1990.

The regressions in (22), (24), (30)-(33), and (35)-(37) that relate the log-change in average human capital, average schooling, average experience, and aggregate 
employment to the log-change in average wages, the price of labor, and the price of human capital are estimated using generalized two-stage least-squares (G2SLS). G2SLS estimation is necessary because right-hand-side variables in these regressions are endogenous and measured with error. Endogeneity arises because workers may move to cities that experience above average exogenous productivity growth. One reason for measurement error in the human capital variable is that it is estimated using individuallevel wage-regressions. Measurement error in the aggregate employment variable arises because the data does not distinguish between full-time and part-time jobs. G2SLS estimation also takes into account heteroskedasticity that arises because left-hand side variables obtained from individual-level wage-regressions are estimated with different precision depending on the number of individual observations per city. The instruments we use for G2SLS estimation are the demographic and ethnic structure of cities in 1970 from the 1970 US Census. For the demographic structure we use the share of individuals in each 5-year cohort between 15 and 70 years (11 variables); the idea to use demographic structure as an instrument comes from Moretti (1998). For the ethnic structure we use the share of individuals that identified themselves as: White; Black; Hispanic; Indian or Eskimo; Japanese, Chinese, or Filipino; and Pacific Islander or Hawaiian (6 variables). Our instruments predict 42 percent of the variation of aggregate employment and 48 percent of the variation of average years of schooling across cities for the 20-year period 1970-1990. We test for exogeneity of the instruments used in each estimating-equation using the Sargan (1988) test and find that exogeneity can never be rejected at the 95-percent significance level. To check the robustness of our key results we also re-estimate key equations using only the 11 demographic variables as instruments. Our demographic instruments predict 37 percent of the variation of aggregate employment and 42 percent of the variation of average schooling across cities for 1970-1990. For comparisons, we also estimate some equations using generalized least-squares (GLS).

Individual-level wage-regressions in (25) and (28) are estimated using ordinary least-squares (OLS), and (34) is estimated using nonlinear least-squares (NLLS). There may be some concern that our results for the Mincerian case are driven by biased OLS estimates of the individual return to schooling. We therefore re-estimate city-year specific prices of human capital in (28) after imposing estimates of the individual return to schooling that account for endogenous and mismeasured individual schooling. 


\section{$7 \quad$ Results}

We first discuss the results of the approach using average wages only. Then we turn to the results of the approach based on prices of human capital and labor estimated using individual-level wage-regressions.

\subsection{Results Using Average Wages}

Table 1 contains G2SLS estimates of $\alpha^{A}, \gamma^{A}$, and $\delta$ in (22). All regressions include a constant and dummies for 4 geographic regions (South, West, Midwest, Mountain) to capture geographically different rates of exogenous productivity growth. Our estimate of the strength of scale externalities is 9 percent when we use demographic and ethnic instruments combined, and 8 percent when we use demographic instruments only (both significant at the 5-percent level). The aggregate effect of a one-year increase in average schooling on average wages $\alpha^{A}$ is estimated to be 10 to 11 percent (significant at the 5percent level). Thus, a 10 percent increase in aggregate employment in cities increases average wages by approximately 0.8 percent, while a one-year increase in average schooling in cities increases average wages by approximately 10 percent. Average experience is an insignificant determinant of average wages. The effects of average schooling and aggregate employment on average wages increase when we drop the geographic dummies (not in the table). Notice that GLS estimates of $\alpha^{A}, \gamma^{A}$, and $\delta$ in Table 1 are smaller than G2SLS estimates. This suggests that GLS estimates are downward biased by measurement error.

Table 2 contains G2SLS estimates of $\alpha^{E}, \gamma^{E}$, and $\delta$ in (24). All regressions include a constant and dummies for 4 geographic regions. The time-invariant labor-force composition used to calculate (23) is the "average" composition of 1970 and 1990. This "average" composition is obtained by averaging city-year specific shares $l_{c t}(S, E ; X)$ for 1970 and 1990. Results do not change however if we use the 1970 or 1990 composition instead. The strength of externalities to average schooling $\alpha^{E}$ is estimated to be 2 percent with a standard error of 3 percent when we use demographic and ethnic instruments combined, and falls to 1 percent when we use demographic instruments only. Both estimates are insignificantly different from zero at the 5-percent level. Estimates of the strength of scale externalities $\delta$ are very similar to the values obtained using (22). Estimates of (22) and (24) for the pooled 10-year periods 1970-1980 and 1980-1990 are similar to the values obtained for the 20-year period 1970-1990. Standard errors 
increase however. For example, our estimate of the aggregate effect of average schooling on average wages is 13 percent with a standard error of 4 percent using demographic and ethnic instruments combined, and 12 percent with a standard error of 5 percent using demographic instruments only (not in the table)

Table 3 contains G2SLS estimates of $\alpha^{E}, \gamma^{E}$, and $\delta$ in (24) using data for white males only. The time-invariant labor-force composition used is the "average" composition for 1970 and 1990. Results basically mirror those obtained for the full sample. The estimate of externalities to average schooling in cities is 2 percent with a standard error of 2.5 percent. Average schooling externalities in cities are therefore insignificantly different from zero at the 5-percent level. Estimated scale externalities are 8 percent (significant at the 5-percent level).

Table 4 contains G2SLS estimates of $\alpha^{E}, \gamma^{E}$, and $\delta$ using (24) with the logchange of adjusted average wages holding labor-force composition constant $\Delta \ln \hat{w}_{c t}^{F A}$ on the left-hand side. City-year specific adjusted average wages $\hat{w}_{c t}^{F A}$ are calculated as in (26) using the "average" labor-force composition for 1970 and 1990. Adjustments for time-region-schooling-experience specific wage-differentials associated with gender, race, and marital status are based on (25). Externalities to average schooling in cities are now estimated to be 1 percent with a standard error of 2 percent using demographic and ethnic instruments combined, and 0.9 percent with a standard error of 2.3 percent using demographic instruments only (both insignificant at the 5-percent level). These estimates are more precise than those obtained with the full sample without adjustments or the white-male sample. The strength of scale externalities is estimated around 7 percent (significant at the 5-percent level) and hence consistent with existing estimates, which range from 4 to 8 percent (Henderson (1988)).

\subsection{Results Using Individual-Level Wage-Regressions}

We first discuss the results using Mincerian wage-regressions. Then we turn to the general case where we allow for decreasing returns to human capital.

Our main results are easily summarized. When we use Mincerian wageregressions we find a considerably larger aggregate return to schooling than with the approach based on average wages. We also find statistically significant schooling externalities between 7 and 10 percent. However, we do not find any significant schooling externalities when we work with individual wage-regressions that allow for 
decreasing returns to human capital. Furthermore, in this case, the aggregate return to schooling becomes very similar to estimates obtained with the approach based on average wages.

\section{Results Using Mincerian Wage-Regressions}

Table 5 contains G2SLS estimates of $\delta$ and $\varepsilon$ using (30). ${ }^{12}$ The regression includes a constant and dummies for 4 geographic regions. The estimate of the strength of scale externalities is 9 percent, and the estimate of the elasticity of average wages with respect to average human capital is 1.85 (both significant at the 5-percent level). The latter estimate implies that a 10-percent increase in average levels of human capital increases average wages by 18.5 percent. Hence, we find increasing aggregate returns to scale to human capital in cities when using the Mincerian approach.

To see whether some of the effect of average human capital on average wages is due to human capital externalities it is necessary to estimate $\theta\left(\varepsilon^{H}\right)$ using (31). Table 6 contains GLS and G2SLS estimates for the 20-year period 1970-1990 and the pooled 10-year periods 1970-1980 and 1980-1990. All regressions include a constant and dummies for 4 geographic regions, and also control for the log-change of aggregate employment over the same time-period. The G2SLS estimate of $\theta\left(\varepsilon^{H}\right)$ is between 0.9 and 0.96 percent (in both cases significant at the 5-percent level). Hence, human capital externalities are significant over the 20-year period 1970-1990, as well as the pooled 10year periods 1970-1980 and 1980-1990. Comparing the G2SLS estimate of $\varepsilon^{H}$ for 1970-1990 in Table 6 with the estimate of $\varepsilon$ for the same time-period in Table 5 yields that almost half of the effect of average human capital on average wages should be interpreted as externalities. Notice also that the GLS estimate of $\varepsilon^{H}$ is below the corresponding G2SLS estimate. This suggests a downward bias due to measurement error when using GLS estimation.

Table 7 presents estimates of the aggregate effect of average years of schooling and experience in cities on average wages using (32). All regressions include a constant and dummies for 4 geographic regions, and also control for the log-change of aggregate employment over the same time-period. G2SLS estimates for the 20-year period 19701990 and the pooled 10-year periods 1970-1980 and 1980-1990 indicate an aggregate

\footnotetext{
${ }^{12}$ OLS estimates of the return to schooling using (28) with the whole sample and controlling for gender, race, and marital status are 0.064 in 1970, 0.062 in 1980, and 0.085 in 1990.
} 
return to schooling $\alpha^{A}$ of 17 to 18 percent (significant at the 5-percent level). Average experience is not a significant determinant of average wages when using G2SLS.

How much of the aggregate return to schooling is due to externalities? This question can be answered by estimating (33). Table 8 contains GLS and G2SLS estimates for the 20-year period 1970-1990 and the pooled 10-year periods 1970-1980 and 1980-1990. All regressions include a constant and dummies for 4 geographic regions, and also control for the log-change of aggregate employment over the same time-period. The G2SLS estimate of externalities to average schooling $\alpha^{E}$ is 10 percent (1970-1990 as well as 1970-1980 and 1980-1990 pooled) when we use demographic and ethnic instruments combined (in both cases significant at the 5-percent level). Estimates fall somewhat when we use demographic instruments only. There are no significant externalities associated with average experience in cities. Notice that GLS estimates are below the corresponding G2SLS estimates, suggesting attenuation bias when using GLS estimation. Finally, it is interesting to compare the strength of average schooling externalities using the Mincerian approach with individual returns to schooling. The Mincerian wage-regressions in (28) yield individual returns to schooling between 6.2 percent (1980) and 8.5 percent (1990). Hence, the external effect of average schooling in cities is estimated to be 10 to 50 percent greater than the individual return to schooling.

Our estimates of average schooling externalities in cities using the Mincerian approach can be compared with the results in Rauch (1993) and Moretti (1998). Both Rauch and Moretti find significant average schooling externalities in US cities. Rauch estimates schooling externalities using data on wages in a cross-section of cities in 1980 and finds values of 3 to 4 percent using GLS. Moretti estimates average schooling externalities using data on a cross-section of cities over the 10-year period 1980-1990; he finds values of 15 to 25 percent (in his Tables 5 and 9) using an instrumental variables approach. ${ }^{13}$ The difference between our G2SLS estimate and the estimate in Rauch is probably due to the fact that he uses GLS. Our GLS estimate in Table 8 (4 percent) is in fact lower than our G2SLS estimate and close to Rauch's results.

There may be some concern that significant average schooling externalities in cities obtained using the Mincerian approach are driven by biased estimates of the individual return to schooling. To address this issue we re-estimate city-year specific

\footnotetext{
${ }^{13}$ These estimates do not control for the change in city-employment or city-population. When Moretti controls for the percentage-change in population across cities (in column 6 of his Table 5), externalities to average years of schooling in cities rise to 41 to 52 percent.
} 
prices of human capital in the Mincerian wage-regressions in (28) after imposing estimates of the individual return to schooling that account for endogeneity and measurement error. The individual return to schooling imposed for 1970 is 0.101 and taken from Angrist and Krueger (1991). The individual return to schooling imposed for 1980 is 0.081, which is an average of the instrumental-variable estimates in Angrist and Krueger (1991) and Staiger and Stock (1997). Finally, the individual return to schooling imposed for 1990 is 0.1 and averages estimates using twins in Rouse (1997) and Ashenfelter and Rouse (1998). In choosing these estimates we used Card (1999) as a guide. Table 9 presents the G2SLS estimate of average schooling externalities in cities for 1970-1990 using (33) together with prices of human capital estimated after imposing the just mentioned individual returns to schooling. The regression includes a constant and 4 geographic dummies, and also controls for the log-change of aggregate employment over the time-period. The average schooling externality is 8 percent with a standard error of 3 percent (significant at the 5-percent level).

We also follow Acemoglu and Angrist (2000) and estimate externalities using data on white males only. This is done in two different ways. Our first approach estimates city-year specific prices of human capital by applying OLS to the Mincerian wage-regressions in (28). The second approach estimates city-year specific prices of human capital using the same estimating-equation but imposing the instrumental-variable estimate of the individual return to schooling for white males in Acemoglu and Angrist. The advantage of the second approach is that endogeneity and mismeasurement of individual schooling are taken into account. The disadvantage is that Acemoglu and Angrist's instrumental-variable estimate assumes that the individual return to schooling remained constant over time. Allowing for time-varying individual returns to schooling and using OLS might therefore be preferable-especially in view of Acemoglu and Angrist's finding (in their Table 6) that instruments for individual schooling do not affect estimates of individual returns to schooling or state-level schooling externalities in a significant way. Table 10 contains the G2SLS estimate of average schooling externalities in cities using demographic and ethnic instruments combined and following the first approach. The strength of average schooling externalities is 8 percent with a standard error of 3 percent (significant at the 5-percent level). Table 11 presents the G2SLS estimate of average schooling externalities in cities using the second approach. The strength of average schooling externalities in this case is 7 percent with a standard error of 3 percent (significant at the 5-percent level). Notice that GLS estimates of average 
schooling externalities in cities are below the corresponding G2SLS estimates in both cases. This suggests a downward bias due to measurement error when using GLS estimation.

The Mincerian approach assumes that the aggregate production function is subject to constant returns to human capital given TFP. This implies that the individual return to schooling in a city is independent of the supply of years of schooling in the city. To test this implication empirically we re-estimate the Mincerian wage-regressions in (28) allowing the individual return to schooling $b$ to vary across cities as well as over time $\ln w_{i c t}=\ln w_{c t}^{H}+b_{c t} S_{i c t}+c_{t} E_{i c t}-e_{t} E_{i c t}^{2}+\sum_{j \in J} d_{j r t} X_{j i c t}+u_{i c t}$. This enables us to relate the change in the OLS estimate of the individual return to schooling $\Delta \hat{b}_{c t}$ across cities between 1970 and 1990 to the change in average years of schooling and experience as well as aggregate employment over the same time-period. Our estimating-equation is $\Delta \hat{b}_{c t}=$ OtherControls $+\mu \Delta \ln L_{c t}+\phi \Delta S_{c t}+\varphi \Delta E_{c t}$. Table 12 presents the results. Our G2SLS estimate of $\phi$ using demographic and ethnic instruments is -0.014 (significant at the 5percent level). ${ }^{14}$ Hence, an increase of average schooling in cities implies lower individual returns to schooling; in particular, a one-year increase in average schooling decreases the individual return to schooling by 1.4 percent. ${ }^{15}$ The effect of average years of experience and aggregate employment on the individual return to schooling (not in the table) is small and statistically insignificant at the 1-percent level. The G2SLS estimate of $\phi$ increases somewhat when we use demographic instruments only. The negative effect of average schooling in cities on individual returns to schooling suggests that it is necessary to estimate human capital externalities using an approach that allows for decreasing returns to human capital.

\section{Results Allowing for Decreasing Returns to Human Capital}

Table 13 contains G2SLS estimates of $\delta$ and $\varepsilon$ using (35). ${ }^{16}$ The estimate of scale externalities is identical to the estimate for the Mincerian case in Table 5 and similar to

\footnotetext{
${ }^{14}$ The effect of the change in average schooling on $\Delta \ln \hat{w}_{c t}^{n}$ remains significantly positive.

${ }^{15}$ Bils and Klenow (2000) analyze the relationship between average years of schooling and individual returns to schooling estimated using Mincerian wage-regressions in a cross-section of countries. They find that higher average levels of schooling are associated with lower individual returns to schooling. Rauch (1993) and Acemoglu and Angrist (2000) do not find any significant relationship at the US city-level and the US state-level respectively.

${ }^{16}$ Estimation of individual-level wage-regressions that allow for decreasing returns to human capital in (34) yields that all of the 519 values for $w_{c t}^{L}$ (173 cities in 1970, 1980, and 1990) are positive and 493 are significantly positive at the 5-percent level. The joint hypothesis that all prices of labor are zero-which implies the Mincerian case—can be rejected at the 0.1-percent level.
} 
the estimate using average wages in Table 1. The estimate of the elasticity of average wages with respect to average human capital using demographic and ethnic instruments is 0.69 (significant at the 5-percent level) and hence much lower than in the Mincerian case in Table 5 (1.85). This estimate implies that a 10-percent increase in average levels of human capital increases average wages by 6.9 percent. Hence, we now find decreasing aggregate returns to scale to human capital in cities-not increasing returns as in the Mincerian case. The estimate of $\varepsilon$ using demographic instruments only is 0.62 (significant at the 5-percent level).

To estimate the strength of human capital externalities $\theta$ in cities we need to estimate $\varepsilon^{H}$ and $\varepsilon^{L}$ using (36) and (37). Table 14 summarizes the results. Recall that constant returns to human capital given TFP (perfect substitutability) implies $\varepsilon^{H}=\varepsilon^{L}$, while decreasing returns to human capital given TFP implies $\varepsilon^{H}<\varepsilon^{L}$. The G2SLS estimates using demographic and ethnic instruments yield $\hat{\varepsilon}^{H}<\hat{\varepsilon}^{L}$. Furthermore, the hypothesis $\varepsilon^{H}=\varepsilon^{L}$ can be rejected in favor of $\varepsilon^{H}<\varepsilon^{L}$ at the 1 -percent level. The G2SLS estimate of $\varepsilon^{H}$ implies that the effect of average human capital in cities on the price of human capital is significantly negative-not significantly positive as in the Mincerian case in Table 6. Hence, the price of (return to) human capital in a city falls as the average level of human capital increases. The G2SLS estimate of the effect of an increase in average human capital on the price of labor is significantly positive. G2SLS estimates using demographic instruments only also yield that the hypothesis $\varepsilon^{H}=\varepsilon^{L}$ can be rejected in favor of $\varepsilon^{H}<\varepsilon^{L}$ at the 1-percent level. Furthermore, the effect of average human capital in cities on the price of human capital (labor) remains significantly negative (positive) when using demographic instruments only. The main result of using demographic instruments only is that standard errors increase. Estimates of $\varepsilon^{H}$ and $\varepsilon^{L}$ for the pooled 10-year periods 1970-1980 and 1980-1990 in Table 15 are similar to those obtained for 1970-1990.

Estimates of $\varepsilon^{H}$ in Tables 14 and 15 yield that an increase in average human capital in cities decreases the price of (return to) human capital. Human capital externalities in cities - if any-are therefore not sufficiently strong to offset decreasing returns to human capital holding TFP constant. To obtain a point estimate and standard error for $\theta$, we simulate the left-hand side of (19). This requires the estimated joint asymptotic distribution of $\hat{\varepsilon}_{L}$ and $\hat{\varepsilon}_{H}$ obtained using (36) and (37) and the $\hat{\lambda}$ s obtained using (38). The result for 1970-1990 is an estimate of $\theta$ equal to 1.5 percent with a standard error of 31 percent. This compares to an estimate of 90 percent with a standard 
error of 41 percent in the Mincerian case in Table 6. Hence, the estimate of the strength of human capital externalities $\theta$ is both much lower and more precise when we do not impose constant returns to human capital given TFP (perfect substitutability).

The alternative approach to estimating human capital externalities $\theta$ in (21) compares the partial elasticity of average wages with respect to average human capital estimated using (35) to the average share of human capital in wages. Averaging $\hat{\lambda}_{c t}$ in (38) across cities and years (1970, 1980, and 1990) yields an estimate of the average share of human capital in wages of 65 percent. Estimates of $\varepsilon$ in Table 13 are between 69 and 62 percent. Hence, the alternative point estimate of the strength of human capital externalities in cities is between -3 and 4 percent.

To estimate the strength of average schooling externalities $f \theta$ in cities it is necessary to estimate $f$ in (39). Table 16 reports that a one-year increase in average schooling raises average human capital by 14 percent. Hence, our point estimates of $\theta$ between -3 and 4 percent imply average schooling externalities $\hat{f} \hat{\theta}$ between -0.5 and 0.6 percent. Relaxing the assumption of constant returns to human capital given TFP therefore yields much lower average schooling externalities in cities than the Mincerian approach in Tables 8 to 11 ( 7 to 10 percent). ${ }^{17}$

The aggregate effect of average years of schooling in cities on average wages can be obtained by estimating (40). Table 17 summarizes the results. The G2SLS estimate of the aggregate return to average schooling in cities is 10 percent for 19701990. This estimate is considerably smaller than the values obtained using the Mincerian approach in Table 7 (17 to 18 percent).

\section{Human Capital and Average Labor Productivity}

There is by now a quite extensive literature estimating the effect of average years of schooling on average labor productivity using country-level data. A survey and new estimates using an improved data set can be found in de la Fuente and Domenech (2000). Estimates of the effect of one-year increase in average schooling on average labor productivity are around 4 percent when the increase in the physical capital intensity induced by higher average schooling is taken into account.

\footnotetext{
${ }^{17} \mathrm{We}$ also estimate average schooling externalities in cities assuming constant returns to human capital given TFP but not that human capital is essential. This is done by estimating (36) and (37) jointly, assuming $\varepsilon^{H}=\varepsilon^{L}$ and substituting $f \Delta S+g \Delta E$ for $\Delta \ln h$ on the right-hand side. In this case the G2SLS estimate of average schooling externalities $f \theta$ in cities is 9 percent with a standard error of 3 percent using geographic dummies.
} 
To compare our results with country-level estimates it is necessary to translate our estimates of the effects of human capital on wages into effects on average labor productivity when physical capital is a production factor. The simplest way to do so is by assuming that the aggregate production function is such that the elasticity of output with respect to physical capital is constant over time (but may vary across cities). In this case competitive markets imply that average wages are linked to average labor productivity by $w_{c t}=\left(1-b_{c}\right) Y_{c t} / L_{c t}$, where $b_{c}$ is the time-invariant elasticity of output with respect to physical capital in city $c$. Hence, the elasticity of average labor productivity with respect to average human capital is identical to the elasticity of average wages with respect to average human capital. This implies that our estimate of the elasticity of average labor productivity with respect to average human capital in US cities is 62 to 69 percent (Table 13). Furthermore, our estimate of the effect of a one-year increase in average schooling on average labor productivity in cities is 10 to 11 percent (Table 1 and 17). Physical capital mobility across cities implies that both estimates include the increase in the physical capital intensity induced by higher average human capital. Finally, we can also estimate the share of human capital in aggregate income by multiplying the labor-share (0.7) with the share of human capital in wages $(0.65$ for 1970-1990). This yields a share of human capital in aggregate income of 45 percent.

\section{Summary}

We estimate the aggregate return to average schooling and returns to scale to human capital in US cities between 1970 and 1990. Our estimates indicate that a one-year increase in average schooling raises average labor productivity by 8 to 11 percent. Returns to scale to human capital are between 62 and 69 percent.

We also analyze the empirical relationship between individual returns to human capital and average levels of human capital in US cities. Our main finding is that higher average levels of human capital imply lower individual returns. Estimating individual returns with Mincerian wage-regressions, we find that a one-year increase in average schooling in a city decreases individual returns to schooling by 1.4 percent.

Our main theoretical contribution is to show how human capital externalities can be identified in a framework where workers with different human capital may be imperfect substitutes. Our simplest approach looks at how average wages holding laborforce composition constant are affected by average schooling. One advantage of this approach is that it is not necessary to estimate the individual return to human capital. 
Nor is it necessary to specify how individual schooling and experience affect individual wages. Furthermore, the approach works for arbitrary aggregate production functions within the human capital framework of modern growth theory. Our preferred estimate of the external effect of a one-year increase in average schooling in a city on average labor productivity is 1 percent with a standard error of 2 percent. 


\section{References}

Acemoglu, Daron and Joshua Angrist (2000) "How Large are the Social Returns to Education: Evidence from Compulsory Schooling Laws," Mimeo, MIT, January.

Acemoglu, Daron (1996) "A Microfoundation for Social Increasing Returns to Human Capital Accumulation,” Quarterly Journal of Economics 111, pp. 78-93.

Angrist, Joshua and Alan Krueger (1991) "Does Compulsory Schooling Attendance Affect Schooling and Earning?" Quarterly Journal of Economics 106, pp. 9791014.

Ashenfelter, Orley and Cecilia Rouse (1998) "Income, Schooling and Ability: Evidence from a New Sample of Identical Twins," Quarterly Journal of Economics 113, pp. 253-284.

Barro, Robert (1991) "Economic Growth in a Cross-Section of Countries," Quarterly Journal of Economics 106, pp. 407-443.

Board of Governors of the Federal Reserve System (1997), Flow of Funds Accounts of the United States, 1982-1990, Washington DC.

Bils, Mark and Peter Klenow (2000) "Does Schooling Cause Growth?" Mimeo, University of Chicago, January.

Card, David (1999) "The Causal Effect of Education on Earnings" in Orley Ashenfelter and David Card Handbook of Labor Economics, North Holland, Amsterdam.

Ciccone, Antonio (1997) "Dynamic Externalities and Spatial Technology Diffusion Across US Counties," Mimeo, University of California, Berkeley, November.

Ciccone, Antonio, Giovanni Peri, and Douglas Almond (1999) "Capital, Wages, and Growth: Theory and Evidence," CEPR Working Paper 2199, May.

Conley, Timothy, Frederick Flier, and Grace Tsiang (1999) "Local Market Human Capital and the Spatial Distribution of Productivity in Malaysia," Mimeo, Northwestern University, February.

de la Fuente, Angel and Rafael Domenech (2000) "Human Capital and Growth: How Much Difference Does Data Quality Make?" Mimeo, Instituto de Análisis Económico (CSIC), Barcelona.

Glaeser, Edward, Heidi Kallal, José Scheinkman, and Andrei Shleifer (1992) "Growth in Cities," Journal of Political Economy 100, pp. 1126-1151.

Henderson, Vernon (1986) "Efficiency of Resource Usage and City Size," Journal of Urban Economics 18, pp. 23-56.

Henderson, Vernon (1988) Urban Development: Theory, Fact, and Illusion, Oxford University Press, Oxford, UK. 
Henderson, Vernon, Ari Kuncoro, and Matt Turner (1995), "Industrial Development in Cities," Journal of Political Economy 103, pp. 1067-1081.

Islam, Nazrul (1995) “Growth Empirics: A Panel Data Approach,” Quarterly Journal of Economics 82, pp. 34-56.

Jacobs, Jane (1969) The Economy of Cities, Random House, New York

Jacobs, Jane (1984) Cities and the Wealth of Nations, Random House, New York

Krugman, Paul (1992) "Increasing Returns and Economic Geography," Journal of Political Economy 99, pp. 483-499.

Lucas, Robert E. (1988) "On the Mechanics of Economic Development," Journal of Monetary Economics 22, pp. 3-41.

Lucas, Robert E. (1999) "Externalities and Cities," Mimeo, University of Chicago, October.

Mankiw, N. Gregory, David Romer, and David Weil (1992) "A Contribution to the Empirics of Economic Growth," Quarterly Journal of Economics 107, pp. 407437.

Marshall, Alfred (1890) Principles of Economics, Macmillan, London.

Mincer, Jacob (1974), Schooling, Experience, and Earnings, Columbia University Press, New York.

Moomaw, Ronald (1981), "Productivity and City Size: A Critique of the Evidence," Quarterly Journal of Economics 95, pp. 194-223.

Moretti, Enrico (1998) "Social Returns to Education and Human Capital Externalities: Evidence from Cities," Mimeo, University of California, Berkeley, November.

Rauch, James (1993) "Productivity Gains from Geographic Concentration in Cities," Journal of Urban Economics 34, pp. 380-400.

Rebelo, Sergio (1991) "Long-Run Policy Analysis and Long-Run Growth," Journal of Political Economy 99, pp. 500-521.

Roback, Jennifer (1982) "Wages, Rents, and the Quality of Life," Journal of Political Economy 90, pp. 1257-1278.

Romer, Paul (1986) "Increasing Returns and Long-Run Growth," Journal of Political Economy 98, pp. 1002-1037.

Rouse, Cecilia (1997) "Further Estimates on the Economic Return to Schooling from a New Sample of Twins," Discussion Paper Industrial Relation Section, Princeton University, September.

Sargan, Dennis (1988) Lectures on Advanced Econometric Theory, Basil Blackwell, Oxford. 
Simon, Curtis (1998) "Human Capital and Metropolitan Employment Growth," Journal of Urban Economics 43, pp. 223-243.

Staiger, Douglas and James Stock (1997) "Instrumental Variables Regressions with Weak Instruments," Econometrica 65, pp. 557-586.

Segal, David (1976), "Are there Returns to City Size?" Review of Economics and Statistics 58, pp. 234-251.

Sveikauskas, Leo (1975), “The Productivity of Cities," Quarterly Journal of Economics 89, pp. 393-413.

Temple, Jonathan (1998) "Robustness Tests of the Augmented Solow Model," Journal of Applied Econometrics 13, pp. 361-375.

U.S. Bureau of Census (1970), Census of Population and Housing, United States.

U.S. Bureau of Census (1980), Census of Population and Housing, United States.

U.S. Bureau of Census (1990), Census of Population and Housing, United States.

US Department of Commerce (1992), Economics and Statistics Administration, Bureau of Economic Analysis, Regional Economic Measurement Division, REIS CDROM. 


\section{Appendix}

\section{A1 Tables}

Table 1: Estimates of $\alpha^{A}, \gamma^{A}$ and $\delta$ Using Average Wages

\begin{tabular}{|l|c|c|c|}
\hline & $\hat{\alpha}^{A}(1970-1990)$ & $\hat{\gamma}^{A}(1970-1990)$ & $\hat{\delta}(1970-1990)$ \\
\hline GLS with GeoControls & $0.04(0.03)$ & $0.005(0.008)$ & $0.07^{*}(0.03)$ \\
\hline G2SLS with GeoControls & $0.11^{*}(0.03)$ & $0.007(0.01)$ & $0.09^{*}(0.04)$ \\
\hline $\begin{array}{l}\text { G2SLS with GeoControls \& } \\
\text { Demographic Instruments Only }\end{array}$ & $0.10^{*}(0.04)$ & $0.006(0.01)$ & $0.08^{*}(0.04)$ \\
\hline
\end{tabular}

Notes: The equation estimated is (22) with data on 173 cities. Standard errors in brackets. All regressions include a constant. "GeoControls" refers to dummies for 4 geographic regions (South, West, Midwest, Mountain). The instruments used in the second row are 11 demographic composition variables and 6 ethnic composition variables in 1970. The instruments used in the third row are the 11 demographic composition variables only. The Sargan (1988) test of exogeneity of instruments yields that exogeneity cannot be rejected at the 95-percent significance level. "*” denotes estimates that are significantly different from zero at the 5-percent level.

Table 2: Estimates of $\alpha^{E}, \gamma^{E}$ and $\delta$ Using Average Wages Holding Labor-Force Composition Constant

\begin{tabular}{|l|c|c|c|}
\hline & $\begin{array}{c}\hat{\alpha}^{E}(1970- \\
1990)\end{array}$ & $\hat{\gamma}^{E}(1970-1990)$ & $\hat{\delta}(1970-1990)$ \\
\hline GLS with GeoControls & $0.011(0.027)$ & $0.001(0.01)$ & $0.08^{*}(0.02)$ \\
\hline G2SLS with GeoControls & $0.02(0.03)$ & $0.008(0.01)$ & $0.1^{*}(0.03)$ \\
\hline $\begin{array}{l}\text { G2SLS with GeoControls \& } \\
\text { Demographic Instruments Only }\end{array}$ & $0.01(0.035)$ & $0.004(0.01)$ & $0.09^{*}(0.03)$ \\
\hline
\end{tabular}

Notes: The equation estimated is (24) with data on 173 cities. Standard errors in brackets. All regressions include a constant. "GeoControls" refers to dummies for 4 geographic regions (South, West, Midwest, Mountain). The instruments used in the second row are 11 demographic composition variables and 6 ethnic composition variables in 1970. The instruments used in the third row are the 11 demographic composition variables only. The Sargan (1988) test of exogeneity of instruments yields that exogeneity cannot be rejected at the 95-percent significance level. “*” denotes estimates that are significantly different from zero at the 5-percent level.

Table 3: Estimates of $\alpha^{E}, \gamma^{E}$ and $\delta$ Using Average Wages Holding Labor-Force Composition Constant with White Males Only

\begin{tabular}{|l|c|c|c|}
\hline & $\hat{\alpha}^{E}(1970-1990)$ & $\hat{\gamma}^{E}(1970-1990)$ & $\hat{\delta}(1970-1990)$ \\
\hline G2SLS with GeoControls & $0.02(0.025)$ & $-0.001(0.01)$ & $0.08^{*}(0.025)$ \\
\hline
\end{tabular}

Notes: The equation estimated is (24) with data on 173 cities. Standard errors in brackets. The regression includes a constant. "GeoControls" refers to dummies for 4 geographic regions (South, West, Midwest, Mountain). The instruments used are 11 demographic composition variables and 6 ethnic composition variables in 1970. The Sargan (1988) test of exogeneity of instruments yields that exogeneity cannot be rejected at the 95-percent significance level. "*" denotes estimates that are significantly different from zero at the 5-percent level.

Table 4: Estimates of $\alpha^{E}, \gamma^{E}$ and $\delta$ Using Adjusted Average Wages Holding LaborForce Composition Constant

\begin{tabular}{|l|c|c|c|}
\hline & $\hat{\alpha}^{E}(1970-1990)$ & $\hat{\gamma}^{E}(1970-1990)$ & $\hat{\delta}(1970-1990)$ \\
\hline G2SLS with GeoControls & $0.01(0.02)$ & $0.001(0.01)$ & $0.07^{*}(0.02)$ \\
\hline $\begin{array}{l}\text { G2SLS with GeoControls \& } \\
\text { Demographic Instruments Only }\end{array}$ & $0.009(0.023)$ & $0.0012(0.02)$ & $0.075^{*}(0.03)$ \\
\hline
\end{tabular}

Notes: The equation estimated is (24) with adjusted average wages holding labor-force composition constant. Adjusted average wages are calculated using (25) and (26). Estimation uses data on 173 cities. Standard errors in brackets. All regressions include a constant. "GeoControls" refers to 
dummies for 4 geographic regions (South, West, Midwest, Mountain). The instruments used in the first row are 11 demographic composition variables and 6 ethnic composition variables in 1970. The instruments used in the second row are the 11 demographic composition variables only. The Sargan (1988) test of exogeneity of instruments yields that exogeneity cannot be rejected at the 95-percent significance level. "*” denotes estimates that are significantly different from zero at the 5-percent level.

Table 5: Estimates of $\varepsilon, \delta$ for the Case of Perfect Substitutability

\begin{tabular}{|l|c|c|}
\hline & $\hat{\varepsilon}(1970-1990)$ & $\hat{\delta}(1970-1990)$ \\
\hline G2SLS with GeoControls & $1.85^{*}(0.44)$ & $0.09^{*}(0.04)$ \\
\hline
\end{tabular}

Notes: The equation estimated is (30) with data on 173 cities. Standard errors in brackets. The regression includes a constant. "GeoControls" refers to dummies for 4 geographic regions (South, West, Midwest, Mountain). Instruments used are 11 demographic composition variables and 6 ethnic composition variables in 1970. The Sargan (1988) test of exogeneity of instruments yields that exogeneity cannot be rejected at the 95-percent significance level. “*” denotes estimates that are significantly different from zero at the 5-percent level.

Table 6: Estimates of $\varepsilon^{H}$ for the Case of Perfect Substitutability

\begin{tabular}{|l|c|c|}
\hline & $\hat{\varepsilon}^{H}(1970-1990)$ & $\hat{\varepsilon}^{H}(1970-1980 \& 1980-1990$ pooled $)$ \\
\hline GLS with GeoControls & $0.21(0.2)$ & $0.09(0.25)$ \\
\hline G2SLS with GeoControls & $0.9^{*}(0.41)$ & $0.96^{*}(0.48)$ \\
\hline
\end{tabular}

Notes: The equation estimated is (31) with data on 173 cities. Standard errors in brackets. All regressions include a constant and control for the log-change of aggregate employment in cities. "GeoControls" refers to dummies for 4 geographic regions (South, West, Midwest, Mountain). Instruments used are 11 demographic composition variables and 6 ethnic composition variables in 1970. The Sargan (1988) test of exogeneity of instruments yields that exogeneity cannot be rejected at the 95 -percent significance level. “*” denotes estimates that are significantly different from zero at the 5-percent level.

Table 7: Estimates of $\alpha^{A}, \gamma^{A}$ for the Case of Perfect Substitutability

\begin{tabular}{|l|c|c|c|c|}
\hline & \multicolumn{2}{|c|}{$1970-1990$} & \multicolumn{2}{c|}{$\begin{array}{c}1970-1980 \& 1980-1990 \\
\text { pooled }\end{array}$} \\
\hline & $\hat{\alpha}^{A}$ & $\hat{\gamma}^{A}$ & $\hat{\alpha}^{A}$ & $\hat{\gamma}^{A}$ \\
\hline GLS with Geo Controls & $\left.0.11^{*} 0.01\right)$ & $0.01^{*}(0.003)$ & $0.12^{*}(0.02)$ & $0.01 *(0.005)$ \\
\hline G2SLS with Geo Controls & $0.17^{*}(0.02)$ & $0.03(0.02)$ & $0.18^{*}(0.03)$ & $0.04(0.03)$ \\
\hline
\end{tabular}

Notes: The equation estimated is (32) with data on 173 cities. Standard errors in brackets. All regressions include a constant and control for the log-change of aggregate employment in cities. "GeoControls" refers to dummies for 4 geographic regions (South, West, Midwest, Mountain). Instruments used are 11 demographic composition variables and 6 ethnic composition variables in 1970. The Sargan (1988) test of exogeneity of instruments yields that exogeneity cannot be rejected at the 95-percent significance level. “*” denotes estimates that are significantly different from zero at the 5-percent level.

Table 8: Estimates of $\alpha^{E}, \gamma^{E}$ for the Case of Perfect Substitutability

\begin{tabular}{|l|c|c|c|c|}
\hline & \multicolumn{2}{|c|}{$1970-1990$} & $1970-1980 \& 1980-1990$ pooled \\
\hline & $\hat{\alpha}^{E}$ & $\hat{\gamma}^{E}$ & $\hat{\alpha}^{E}$ & $\hat{\gamma}^{E}$ \\
\hline GLS with Geo Controls & $0.04^{*}$ & 0.001 & 0.02 & 0.002 \\
& $(0.02)$ & $(0.006)$ & $(0.017)$ & $(0.005)$ \\
\hline G2SLS with Geo Controls & $0.10^{*}$ & 0.01 & $0.10^{*}$ & 0.01 \\
& $(0.03)$ & $(0.01)$ & $(0.04)$ & $(0.01)$ \\
\hline G2SLS with Geo Controls & $0.09^{*}$ & 0.005 & 0.08 & 0.01 \\
\& Demographic Instruments Only & $(0.035)$ & $(0.015)$ & $(0.05)$ & $(0.02)$ \\
\hline
\end{tabular}

Notes: The equation estimated is (33) with data on 173 cities. Standard errors in brackets. All regressions include a constant and control for the log-change of aggregate employment in cities. "GeoControls" refers to dummies for 4 geographic regions (South, West, Midwest, Mountain). The instruments used in the second row are 11 demographic composition variables and 6 ethnic 
composition variables in 1970. The instruments used in the third row are the 11 demographic composition variables only. The Sargan (1988) test of exogeneity of instruments yields that exogeneity cannot be rejected at the 95-percent significance level. "*" denotes estimates that are significantly different from zero at the 5-percent level.

Table 9: Estimates of $\alpha^{E}, \gamma^{E}$ for the Case of Perfect Substitutability Imposing the Individual Return to Schooling

\begin{tabular}{|l|c|c|}
\hline & $\hat{\alpha}^{E}(1970-1990)$ & $\hat{\gamma}^{E}(1970-1990)$ \\
\hline G2SLS with GeoControls & $0.08^{*}(0.03)$ & $0.01(0.01)$ \\
\hline
\end{tabular}

Notes: The equation estimated is (33) with data on 173 cities. Standard errors in brackets. The regression includes a constant and controls for the log-change of aggregate employment in cities. "GeoControls" refers to dummies for 4 geographic regions (South, West, Midwest, Mountain). The instruments used are 11 demographic composition variables and 6 ethnic composition variables in 1970. The individual returns to schooling imposed in (28) are taken from Angrist and Krueger (1991), Staiger and Stock (1997), Rouse (1997), and Ashenfelter and Rouse (1998). The Sargan (1988) test of exogeneity of instruments yields that exogeneity cannot be rejected at the 95-percent significance level. "*" denotes estimates that are significantly different from zero at the 5-percent level.

Table 10: Estimates of $\alpha^{E}, \gamma^{E}$ for the Case of Perfect Substitutability Using White Males Only

\begin{tabular}{|l|c|c|}
\hline & $\hat{\alpha}^{E}(1970-1990)$ & $\hat{\gamma}^{E}(1970-1990)$ \\
\hline GLS with GeoControls & $0.04^{*}(0.016)$ & $0.005(0.004)$ \\
\hline G2SLS with GeoControls & $0.08^{*}(0.03)$ & $0.003(0.007)$ \\
\hline
\end{tabular}

Notes: The equation estimated is (33) with data on 173 cities. Standard errors in brackets. All regressions include a constant and control for the log-change of aggregate employment in cities. "GeoControls" refers to dummies for 4 geographic regions (South, West, Midwest, Mountain). The instruments used are 11 demographic composition variables and 6 ethnic composition variables in 1970. The Sargan (1988) test of exogeneity of instruments yields that exogeneity cannot be rejected at the 95-percent significance level. “*” denotes estimates that are significantly different from zero at the 5-percent level.

Table 11: Estimates of $\alpha^{E}, \gamma^{E}$ for the Case of Perfect Substitutability Using White Males Only and Imposing the A\&A (2000) IV-Estimate of Individual Return to Schooling

\begin{tabular}{|l|c|c|}
\hline & $\hat{\alpha}^{E}(1970-1990)$ & $\hat{\gamma}^{E}(1970-1990)$ \\
\hline GLS with GeoControls & $0.04^{*}(0.016)$ & $0.005(0.005)$ \\
\hline G2SLS with GeoControls & $0.07 *(0.03)$ & $0.005(0.007)$ \\
\hline
\end{tabular}

Notes: The equation estimated is (33) with data on 173 cities. Standard errors in brackets. All regressions include a constant and control for the log-change of aggregate employment in cities. "GeoControls" refers to dummies for 4 geographic regions (South, West, Midwest, Mountain). The instruments used are 11 demographic composition variables and 6 ethnic composition variables in 1970. The instrumental-variable estimate of the individual return to schooling imposed in (28) is taken from Acemoglu and Angrist (2000). The Sargan (1988) test of exogeneity of instruments yields that exogeneity cannot be rejected at the 95-percent significance level. "**" denotes estimates that are significantly different from zero at the 5-percent level.

Table 12: Effect of Average Schooling in Cities on the Individual Return to Schooling Estimated Using Mincerian Wage-Regressions

\begin{tabular}{|l|c|}
\hline & $\hat{\phi}(1970-1990)$ \\
\hline GLS with GeoControls & $0.008(0.006)$ \\
\hline G2SLS with GeoControls & $-0.014^{*}(0.0065)$ \\
\hline G2SLS with GeoControls \& Demographic Instruments Only & $-0.012(0.007)$ \\
\hline
\end{tabular}

Notes: The equation estimated is $\Delta \hat{b}_{c t}=$ GeoControls $+\mu \Delta \ln L_{c t}+\phi \Delta S_{c t}+\varphi \Delta E_{c t}+u_{c t}$ where $\Delta \hat{b}_{c t}$ is the OLS estimate of the change in the city-year specific individual return to schooling between 1970 and 
1990 using Mincerian wage-regressions; the Mincerian wage-regressions are specified as in (28) except that the individual return to schooling is allowed to vary across cities. The equation is estimated with data on 173 cities. Standard errors in brackets. All regressions include a constant. The instruments used in the second row are 11 demographic composition variables and 6 ethnic composition variables in 1970. The instruments used in the third row are the 11 demographic composition variables only. The Sargan (1988) test of exogeneity of instruments yields that exogeneity cannot be rejected at the 95-percent significance level. The effects of the change in average years of experience and aggregate employment in cities, $\hat{\varphi}$ and $\hat{\mu}$ respectively, are statistically insignificant at the 1-percent level. "*" denotes estimates that are significantly different from zero at the 5-percent level.

Table 13: Estimates of $\varepsilon, \delta$ for the Case of Imperfect Substitutability

\begin{tabular}{|l|c|c|}
\hline & $\hat{\varepsilon}(1970-1990)$ & $\hat{\delta}(1970-1990)$ \\
\hline G2SLS with GeoControls & $0.69^{*}(0.24)$ & $0.09 *(0.03)$ \\
\hline G2SLS with GeoControls \& & $0.62 *(0.3)$ & $0.09 *(0.05)$ \\
Demographic Instruments Only & & \\
\hline
\end{tabular}

Notes: The equation estimated is (35) with data on 173 cities. Standard errors in brackets. All regressions include a constant. "GeoControls" refers to dummies for 4 geographic regions (South, West, Midwest, Mountain). Instruments used are 11 demographic composition variables and 6 ethnic composition variables in 1970. The Sargan (1988) test of exogeneity of instruments yields that exogeneity cannot be rejected at the 95-percent significance level. “*” denotes estimates that are significantly different from zero at the 5-percent level.

Table 14: Estimates of $\varepsilon^{H}, \varepsilon^{L}$

\begin{tabular}{|l|c|c|}
\hline & $\hat{\varepsilon}^{H}(1970-1990)$ & $\hat{\varepsilon}^{L}(1970-1990)$ \\
\hline GLS with GeoControls & $0.17(0.34)$ & $0.89(0.79)$ \\
\hline G2SLS with GeoControls & $-2.26^{*}(0.60)$ & $4.24 *(1.27)$ \\
\hline G2SLS with GeoControls \& & $-2.7^{*}(1.3)$ & $4.3^{*}(2.1)$ \\
Demographic Instruments Only & & \\
\hline
\end{tabular}

Notes: The equations estimated are (36) and (37) with data on 173 cities. Standard errors in brackets. All regressions include a constant and control for the log-change of aggregate employment in cities. "GeoControls" refers to dummies for 4 geographic regions (South, West, Midwest, Mountain). Instruments used are 11 demographic composition variables and 6 ethnic composition variables in 1970. The Sargan (1988) test of exogeneity of instruments yields that exogeneity cannot be rejected at the 95-percent significance level. “*” denotes estimates that are significantly different from zero at the 5-percent level.

Table 15: Estimates of $\varepsilon^{H}, \varepsilon^{L}$ for 1970-1980 and 1980-1990 Pooled

\begin{tabular}{|l|c|c|}
\hline & $\hat{\varepsilon}^{H}(1970-1980 \& 1980-$ & $\hat{\varepsilon}^{L}(1970-1980 \& 1980-1990$ \\
& 1990 pooled $)$ & pooled $)$ \\
\hline G2SLS with GeoControls & $-2.16^{*}(0.79)$ & $4.4^{*}(2.22)$ \\
\hline
\end{tabular}

Notes: The equations estimated are (36) and (37) with data on 173 cities. Standard errors in brackets. The regressions include a constant and control for the log-change of aggregate employment in cities. "GeoControls" refers to dummies for 4 geographic regions of the US (South, West, Midwest, Mountain). Instruments used are 11 demographic composition variables and 6 ethnic composition variables in 1970. The Sargan (1988) test of exogeneity of instruments yields that exogeneity cannot be rejected at the 95-percent significance level. “*” denotes estimates that are significantly different from zero at the 5-percent level.

Table 16: Estimates of $f, g$

\begin{tabular}{|l|c|c|}
\hline & $\hat{f}(1970-1990)$ & $\hat{g}(1970-1990)$ \\
\hline GLS & $0.14 *(0.01)$ & $0.01 *(0.01)$ \\
\hline
\end{tabular}

Notes: The equation estimated is (39) with data on 173 cities. Standard errors in brackets. $R^{2}=0.96$. 
Table 17: Estimates of $\alpha^{A}, \gamma^{A}$ for the Case of Imperfect Substitutability

\begin{tabular}{|l|c|c|c|c|}
\hline & \multicolumn{2}{|c|}{$1970-1990$} & \multicolumn{2}{c|}{$1970-1980 \& 1980-1990$ pooled } \\
\hline & $\hat{\alpha}^{A}$ & $\hat{\gamma}^{A}$ & $\hat{\alpha}^{A}$ & $\hat{\gamma}^{A}$ \\
\hline GLS with Geo Controls & $0.05^{*}$ & $0.01^{*}$ & $0.06^{*}$ & 0.008 \\
& $(0.01)$ & $(0.004)$ & $(0.02)$ & $(0.006)$ \\
\hline G2SLS with Geo Controls & $0.10^{*}$ & 0.008 & $0.11^{*}$ & 0.01 \\
& $(0.015)$ & $(0.01)$ & $(0.02)$ & $(0.1)$ \\
\hline G2SLS with Geo Controls \& & $0.10^{*}$ & 0.003 & $0.10^{*}$ & 0.01 \\
Demographic Instruments Only & $(0.025)$ & $(0.015)$ & $(0.035)$ & $(0.15)$ \\
\hline
\end{tabular}

Notes: The equation estimated is (40) with data on 173 cities. Standard errors in brackets. All regressions include a constant and control for the log-change of aggregate employment in cities. "GeoControls" refers to dummies for 4 geographic regions (South, West, Midwest, Mountain). The instruments used in the second row are 11 demographic composition variables and 6 ethnic composition variables in 1970. The instruments used in the third row are the 11 demographic composition variables only. The Sargan (1988) test of exogeneity of instruments yields that exogeneity cannot be rejected at the 95-percent significance level. "*" denotes estimates that are significantly different from zero at the 5-percent level.

\section{A2 Data and Some Statistics}

The data used in the empirical analysis comes from the "Census of Population and Housing" PUMS files. For 1970 we have used the 5-percent sample modifying the extraction code kindly provided by David Card. The geographic identifier used for 1970 is the "County Group Code". For 1980 and 1990 we have used the "Card and Chay" extracts of the 5-percent PUMS (available at ftp://elsa.berkeley.edu/pub/census/) which include the SMSA code as a geographic identifier.

\section{Construction of Cities}

The definition of cities that we use corresponds, with some exceptions, to the US Bureau of Census definition of standard metropolitan statistical areas (SMSAs) in 1990. The PUMS of the 1980 and 1990 US Census have (FIPS) codes identifying the SMSA where individuals live. With this information we can assign individuals in 1980 and 1990 to one of 236 cities. The 1970 US Census does not identify the SMSAs where individuals live, only whether they live in a SMSA or not. Individuals are instead assigned to so-called county groups. County groups can be related to SMSAs by using the so-called county group map (attached to the PUMS in 1970). We match individuals to SMSAs in the following way. When one or more county groups were contained in one SMSA, then we assign individuals located in one of the county groups to the SMSA that contains them. When a county group contained more than one SMSA, then we merged the different SMSAs into one (13 of our 173 cities are obtained this way) applying the same criterion to SMSAs in 1980 and 1990 (to ensure that cities are defined in the same way in 1970,1980, and 1990). Finally, when a county group was contained partly in a SMSA and partly in a non-SMSA area, then we assigned all individuals located in the county group who lived in a SMSA to the SMSA that contained part of the county group. This procedure resulted in 173 cities for 1970, 1980, and 1990. The code to perform the identification and merge of cities is available from us upon request.

\section{Definition of Individual Wages and Schooling}

Hourly wages in a given year have been calculated as yearly salary and wage divided by weeks worked times average hours per week worked in the year. All regressions are run using only 
individuals with positive hours worked and non-negative potential experience. All variables refer to the year previous to the Census. Top-codes differ across years. Individual years of schooling have been obtained in the following way. For 1970 and 1980, we use the variables "Highest Grade Attended" and "Grade" which yields 19 levels of schooling. For 1990, we use the variable "Yearsch" which yields 11 levels of schooling. When we only observe an interval for years of schooling, we use the midpoint of the interval as years of schooling in the individual-level wage-regressions in (28) and (34). Years of experience used in (28) and (34) is potential experience, i.e. age minus years of schooling minus 6. For the individual-level wageregression in (25) we partition years of schooling in 7 intervals [0-4), [4-9), [9-12), [12-14), [14-16), [16-17), and [17 and more) and years of experience in 4 intervals [0-10), [10-20), [20-30), [40-more).

\section{National Wages and Labor-Force Composition by Schooling}

National hourly wages in 1990 US\$ and labor-force composition for 7 educational groups for the whole sample are given in the next table.

\begin{tabular}{|l|c|c|c|c|c|c|}
\hline Years of Schooling & \multicolumn{2}{|c|}{1970} & \multicolumn{2}{c|}{1980} & \multicolumn{2}{c|}{1990} \\
\hline & $\begin{array}{c}\text { National } \\
\text { Shares }\end{array}$ & $\begin{array}{c}\text { Average } \\
\text { Wage }\end{array}$ & $\begin{array}{c}\text { National } \\
\text { Shares }\end{array}$ & $\begin{array}{c}\text { Average } \\
\text { Wage }\end{array}$ & $\begin{array}{c}\text { National } \\
\text { Shares }\end{array}$ & $\begin{array}{c}\text { Average } \\
\text { Wage }\end{array}$ \\
\hline$[0-4)$ & 0.026 & 10.9 & 0.016 & 10.6 & 0.013 & 9.8 \\
\hline$[4-9)$ & 0.11 & 11.1 & 0.05 & 11.1 & 0.03 & 10.5 \\
\hline$[9-12)$ & 0.18 & 11.5 & 0.12 & 10.6 & 0.12 & 10.3 \\
\hline$[12-14)$ (High School) & 0.43 & 12.1 & 0.45 & 10.8 & 0.51 & 10.9 \\
\hline$[14-16)$ & 0.096 & 14.3 & 0.14 & 12.1 & 0.074 & 12.8 \\
\hline$[16-17)$ (College) & 0.08 & 18.7 & 0.11 & 14.7 & 0.17 & 16.4 \\
\hline$[17$ and more) & 0.07 & 20.7 & 0.10 & 16.9 & 0.085 & 20.6 \\
\hline
\end{tabular}

\section{National Adjusted Wages}

National average values of the OLS estimates of the $\omega \mathrm{s}$ in (25) in 1990 US\$ for the whole sample are given in the next table. Equation (25) is set up so that the constant corresponds to married white males. Average values by educational group are calculated using the national distribution of the labor-force by experience and weighting the value estimated for each city by its employment.

\begin{tabular}{|l|c|c|c|}
\hline Years of Schooling & $\mathbf{1 9 7 0}$ & $\mathbf{1 9 8 0}$ & $\mathbf{1 9 9 0}$ \\
\hline$[0-4)$ & 11.5 & 11.0 & 10.5 \\
\hline$[4-9)$ & 12.5 & 11.9 & 11.1 \\
\hline$[9-12)$ & 13.7 & 13.3 & 11.4 \\
\hline$[12-14)$ (High School) & 15.0 & 14.3 & 14.5 \\
\hline$[14-16)$ & 17.3 & 16.1 & 16.1 \\
\hline$[16-17)($ College $)$ & 22.4 & 21.2 & 21.0 \\
\hline$[17$ and more) & 24.6 & 22.5 & 26.5 \\
\hline
\end{tabular}

\section{Simulating the strength of human capital externalities using (19)}

Estimating (36) and (37) using G2SLS we obtain the point-estimates and the estimated variance-covariance matrix of $\varepsilon^{H}$ and $\varepsilon^{L}$. We then simulate 10000 extractions of $\varepsilon^{H}$ and $\varepsilon^{L}$ from a jointly normal distribution with expectation equal to the point-estimates and a variancecovariance matrix equal to the estimated variance-covariance matrix. These extractions are 
combined with the average share of human capital in wages and (19) to simulate the distribution of $\hat{\theta}$. We obtain the average share of human capital by averaging (38) across cities and years. The point-estimate and standard deviation reported in the text are the mean and standard deviation of the simulated distribution.

\section{A3 Cities and Key Aggregate Variables}

\begin{tabular}{|c|c|c|c|c|c|c|}
\hline \multirow[t]{2}{*}{ City Name } & \multicolumn{2}{|c|}{$\begin{array}{l}\text { Average } \\
\text { Years of } \\
\text { Schooling } \\
\end{array}$} & \multicolumn{2}{|c|}{$\begin{array}{l}\text { Average } \\
\text { Years of } \\
\text { Experience }\end{array}$} & \multicolumn{2}{|c|}{$\begin{array}{l}\text { Total Private, Non- } \\
\text { Agricultural } \\
\text { Employment }\end{array}$} \\
\hline & 70 & '90 & 70 & '90 & '70 & '90 \\
\hline Abilene, TX & 11.6 & 13.2 & 24.1 & 18.4 & 54707 & 91746 \\
\hline Akron, $\mathrm{OH}$ & 12.1 & 13.1 & 22.7 & 18.8 & 237978 & 285068 \\
\hline Albany-Schenectady-Troy, NY & 12.3 & 13.4 & 23.6 & 19.5 & 262619 & 384949 \\
\hline Albuquerque, NM & 12.7 & 13.3 & 21.0 & 18.7 & 100206 & 244273 \\
\hline Allentown-Bethlehem-Easton, PA-NJ & 11.3 & 12.9 & 25.3 & 20.0 & 238793 & 303955 \\
\hline Altoona, PA & 11.4 & 12.6 & 24.1 & 19.5 & 49094 & 55627 \\
\hline Amarillo, TX & 12.0 & 12.9 & 21.2 & 19.3 & 53301 & 82711 \\
\hline Anaheim-Santa Ana, CA & 12.6 & 13.1 & 20.0 & 18.4 & 429256 & 1405209 \\
\hline Appleton-Oshkosh-Neenah, WI & 11.7 & 12.9 & 22.3 & 18.3 & 99351 & 163027 \\
\hline Atlanta, GA & 11.9 & 13.5 & 20.6 & 17.9 & 703363 & 1580647 \\
\hline Atlantic City, NJ & 10.8 & 12.6 & 25.7 & 20.4 & 131011 & 236189 \\
\hline Augusta, GA-SC & 11.1 & 12.9 & 22.5 & 19.1 & 88932 & 177811 \\
\hline Austin, TX & 12.4 & 13.5 & 20.5 & 17.1 & 108915 & 351303 \\
\hline Bakersfield, CA & 11.6 & 12.9 & 23.6 & 19.8 & 84895 & 187927 \\
\hline Baltimore, MD & 11.2 & 13.2 & 23.4 & 18.7 & 748907 & 1136605 \\
\hline Baton Rouge, LA & 12.2 & 12.9 & 21.7 & 17.4 & 108653 & 217277 \\
\hline Beaumont-Port Arthur, TX & 11.2 & 12.7 & 23.3 & 20.0 & 116527 & 143500 \\
\hline Billings, MT & 12.2 & 13.5 & 22.6 & 17.7 & 54915 & 91819 \\
\hline Biloxi-Gulfport, MS & 11.5 & 12.8 & 22.6 & 19.9 & 39027 & 68701 \\
\hline Binghamton, NY & 12.3 & 13.4 & 22.7 & 18.8 & 92062 & 117649 \\
\hline Birmingham, AL & 11.4 & 13.0 & 23.0 & 19.6 & 283762 & 418355 \\
\hline Bloomington-Normal, IL & 12.3 & 13.5 & 22.3 & 17.9 & 36163 & 66448 \\
\hline Boise City, ID & 12.8 & 13.3 & 20.6 & 17.6 & 41377 & 112395 \\
\hline Boston, MA & 12.3 & 13.8 & 23.8 & 18.1 & 1716968 & 2314349 \\
\hline Bridgeport, CT & 11.6 & 12.9 & 25.2 & 21.1 & 340672 & 447286 \\
\hline Brownsville-Harlingen, TX & 9.2 & 10.7 & 24.9 & 20.3 & 70841 & 179994 \\
\hline Buffalo, NY & 11.7 & 13.2 & 24.4 & 19.8 & 385600 & 450640 \\
\hline Canton, OY & 11.6 & 12.6 & 22.9 & 19.1 & 144914 & 176241 \\
\hline Cedar Rapids, IA & 12.3 & 13.2 & 20.7 & 19.8 & 68057 & 98237 \\
\hline Champaign-Urbana-Rantoul, IL & 13.3 & 13.9 & 18.5 & 17.9 & 38843 & 72901 \\
\hline Charleston, SC & 10.9 & 12.9 & 22.3 & 18.2 & 85389 & 195445 \\
\hline Charlotte-Gastonia-Rock Hill, NC-SC & 11.8 & 12.7 & 21.4 & 18.5 & 380775 & 669127 \\
\hline Chattanooga, TN-GA & 11.1 & 12.4 & 23.5 & 21.0 & 141885 & 202487 \\
\hline Chicago, IL & 11.9 & 13.2 & 23.3 & 19.3 & 2620409 & 3262950 \\
\hline Cincinnati, OH-KY-IN & 11.7 & 13.1 & 22.8 & 18.8 & 519052 & 768186 \\
\hline Cleveland, $\mathrm{OH}$ & 11.9 & 13.1 & 23.6 & 19.5 & 848369 & 962555 \\
\hline Colorado Springs, CO & 12.3 & 13.4 & 22.3 & 19.7 & 87520 & 207905 \\
\hline
\end{tabular}




\begin{tabular}{|c|c|c|c|c|c|c|}
\hline \multirow[t]{2}{*}{ City Name } & \multicolumn{2}{|c|}{\begin{tabular}{|l} 
Average \\
Years of \\
Schooling \\
\end{tabular}} & \multicolumn{2}{|c|}{$\begin{array}{l}\text { Average } \\
\text { Years of } \\
\text { Experience } \\
\end{array}$} & \multicolumn{2}{|c|}{$\begin{array}{l}\text { Total Private, Non- } \\
\text { Agricultural } \\
\text { Employment }\end{array}$} \\
\hline & 70 & '90 & '70 & ‘90 & 670 & '90 \\
\hline Columbia, MO & 12.8 & 13.9 & 19.2 & 13.2 & 22604 & 50780 \\
\hline Columbia, SC & 11.7 & 13.2 & 20.5 & 18.6 & 106882 & 224986 \\
\hline Columbus, $\mathrm{OH}$ & 12.3 & 13.3 & 21.2 & 18.0 & 408761 & 712922 \\
\hline Corpus Christi, TX & 10.8 & 12.6 & 23.5 & 18.4 & 86664 & 132307 \\
\hline Dallas, TX & 11.8 & 13.1 & 21.4 & 17.9 & 987312 & 2082026 \\
\hline Davenport-Rock Island-Moline, IA-IL & 11.8 & 13.1 & 23.6 & 18.4 & 128309 & 164751 \\
\hline Dayton-Springfield, $\mathrm{OH}$ & 11.8 & 13.2 & 22.4 & 19.5 & 350730 & 442932 \\
\hline Decatur, IL & 11.8 & 13.2 & 24.6 & 21.0 & 116410 & 154621 \\
\hline Denver, CO & 12.6 & 13.4 & 20.9 & 18.8 & 437946 & 912957 \\
\hline Des Moines, IA & 12.5 & 13.2 & 22.3 & 18.3 & 142745 & 242171 \\
\hline Detroit, MI & 11.9 & 13.1 & 22.5 & 19.2 & 1578307 & 1993757 \\
\hline Duluth, MN-WI & 12.1 & 12.8 & 24.5 & 18.8 & 81523 & 94318 \\
\hline El Paso, TX & 11.1 & 11.9 & 22.2 & 19.0 & 99848 & 199834 \\
\hline Erie, PA & 12.0 & 13.0 & 24.2 & 20.0 & 100555 & 126113 \\
\hline Eugene-Springfield, OR & 12.6 & 13.2 & 21.5 & 19.3 & 65898 & 123967 \\
\hline Fayetteville, NC & 11.1 & 13.0 & 20.5 & 16.3 & 42539 & 77154 \\
\hline Flint, MI & 11.6 & 12.8 & 21.1 & 19.6 & 144957 & 171398 \\
\hline Fort Lauderdale-Hollywood-P.Beach, FL & 11.7 & 13.0 & 24.4 & 20.3 & 206800 & 583406 \\
\hline Fort Wayne, IN & 12.2 & 12.8 & 21.4 & 19.7 & 141088 & 212278 \\
\hline Fresno, CA & 11.9 & 12.7 & 21.8 & 19.2 & 122350 & 257420 \\
\hline Gainesville, FL & 12.9 & 13.9 & 19.8 & 16.2 & 29092 & 78446 \\
\hline Gary-Hammond, IN & 11.4 & 12.8 & 23.6 & 20.5 & 227318 & 247774 \\
\hline Grand Rapids, MI & 11.8 & 13.1 & 22.9 & 17.7 & 199974 & 396412 \\
\hline Green Bay, WI & 11.9 & 12.8 & 21.3 & 18.2 & 55787 & 108272 \\
\hline $\begin{array}{l}\text { Greensboro-Winston-Salem-High Point, } \\
\text { NC }\end{array}$ & 11.1 & 12.7 & 22.8 & 19.9 & 330504 & 537601 \\
\hline Greenville-Spartanburg, SC & 10.9 & 12.7 & 22.2 & 19.9 & 202077 & 352503 \\
\hline Hamilton-Middletown, $\mathrm{OH}$ & 11.3 & 12.8 & 22.7 & 18.2 & 68885 & 96991 \\
\hline Harrisburg-Lebanon-Carlisle, PA & 11.6 & 12.8 & 23.7 & 19.2 & 191536 & 289589 \\
\hline Hartford, CT & 11.9 & 13.5 & 24.0 & 19.6 & 97244 & 153015 \\
\hline Honolulu, HI & 12.2 & 13.3 & 21.3 & 19.6 & 218323 & 388070 \\
\hline Houston, TX & 11.8 & 12.8 & 20.8 & 18.2 & 829788 & 1728781 \\
\hline Huntington-Ashland, WV-KY-OH & 11.7 & 12.8 & 24.4 & 20.6 & 93553 & 112138 \\
\hline Indianapolis, IN & 11.9 & 12.9 & 22.3 & 18.6 & 428858 & 686737 \\
\hline Jackson, MI & 11.8 & 12.6 & 23.6 & 19.7 & 48035 & 54326 \\
\hline Jackson, MS & 12.1 & 13.8 & 21.4 & 18.5 & 106672 & 175415 \\
\hline Jacksonville, FL & 11.6 & 12.7 & 22.7 & 19.3 & 211580 & 429792 \\
\hline Jersey City, NJ & 10.4 & 12.2 & 26.3 & 20.8 & 252752 & 234772 \\
\hline Johnstown, PA & 11.3 & 12.6 & 24.8 & 21.5 & 76736 & 85583 \\
\hline Kalamazoo, MI & 12.4 & 13.4 & 20.9 & 18.3 & 70735 & 114059 \\
\hline Kansas City, MO-KS & 12.1 & 13.2 & 22.8 & 19.1 & 525933 & 808325 \\
\hline Kenosha, WI & 11.6 & 12.9 & 23.5 & 19.5 & 90329 & 121051 \\
\hline Knoxville, TN & 11.6 & 12.6 & 23.4 & 21.0 & 149498 & 280887 \\
\hline Lafayette, LA & 11.4 & 12.8 & 22.1 & 17.7 & 42068 & 103342 \\
\hline
\end{tabular}




\begin{tabular}{|c|c|c|c|c|c|c|}
\hline \multirow[t]{2}{*}{ City Name } & \multicolumn{2}{|c|}{\begin{tabular}{|l} 
Average \\
Years of \\
Schooling \\
\end{tabular}} & \multicolumn{2}{|c|}{\begin{tabular}{|l|} 
Average \\
Years of \\
Experience
\end{tabular}} & \multicolumn{2}{|c|}{$\begin{array}{l}\text { Total Private, Non- } \\
\text { Agricultural } \\
\text { Employment }\end{array}$} \\
\hline & '70 & '90 & 770 & '90 & 70 & '90 \\
\hline Lafayette, IN & 12.6 & 13.5 & 22.7 & 14.7 & 36562 & 59149 \\
\hline Lancaster, PA & 11.0 & 12.4 & 24.4 & 20.5 & 130428 & 215469 \\
\hline Lansing-East Lansing, MI & 12.5 & 13.5 & 20.2 & 18.0 & 107632 & 177065 \\
\hline Las Vegas, NY & 12.1 & 12.4 & 21.2 & 20.0 & 105346 & 390749 \\
\hline Lawton, OK & 11.7 & 12.2 & 23.6 & 20.8 & 53294 & 86708 \\
\hline Lexington-Fayette, KY & 12.4 & 13.5 & 19.5 & 17.7 & 96774 & 189803 \\
\hline Lima, $\mathrm{OH}$ & 11.7 & 12.3 & 23.4 & 21.9 & 59761 & 76125 \\
\hline Lincoln, NE & 12.8 & 13.5 & 21.0 & 16.9 & 62273 & 111918 \\
\hline Little Rock-North Little Rock, AR & 11.9 & 13.1 & 21.9 & 19.4 & 137982 & 248532 \\
\hline Lorain-Elyria, OH & 11.2 & 12.5 & 23.7 & 20.6 & 79172 & 93067 \\
\hline Los Angeles-Long Beach, CA & 12.3 & 12.4 & 22.1 & 19.1 & 2867092 & 4617235 \\
\hline Louisville, KY-IN & 11.4 & 13.2 & 23.2 & 20.2 & 356409 & 499585 \\
\hline Lubbock, TX & 11.5 & 13.0 & 21.4 & 17.1 & 58604 & 97582 \\
\hline Macon-Warner Robins, GA & 11.1 & 12.8 & 23.7 & 17.1 & 71820 & 115158 \\
\hline Madison, WI & 13.0 & 14.1 & 20.0 & 16.9 & 94819 & 192086 \\
\hline Mansfield, $\mathrm{OH}$ & 11.4 & 12.6 & 22.7 & 19.6 & 52239 & 62090 \\
\hline Memphis, TN-AR-MS & 11.5 & 13.2 & 22.5 & 18.2 & 288933 & 490942 \\
\hline Miami-Hialeah, FL & 11.5 & 12.5 & 24.2 & 21.4 & 552362 & 961182 \\
\hline Milwaukee, WI & 12.0 & 13.2 & 22.7 & 19.0 & 569223 & 786156 \\
\hline Minneapolis-St. Paul, MN-WI & 12.4 & 13.5 & 21.2 & 18.0 & 798927 & 1410586 \\
\hline Modesto, CA & 12.0 & 12.4 & 22.0 & 18.5 & 57558 & 133340 \\
\hline Monroe, LA & 11.5 & 12.9 & 23.6 & 17.8 & 35308 & 56537 \\
\hline Montgomery, AL & 11.3 & 13.1 & 23.7 & 19.3 & 72900 & 121578 \\
\hline Muncie, IN & 11.6 & 12.6 & 22.4 & 19.7 & 94302 & 103926 \\
\hline Nashville, TN & 11.7 & 13.0 & 22.2 & 18.8 & 270000 & 537601 \\
\hline New Orleans, LA & 11.4 & 13.3 & 23.2 & 19.4 & 400789 & 545158 \\
\hline New York, NY & 11.8 & 13.1 & 24.3 & 20.5 & 4008941 & 4057008 \\
\hline Newark, NJ & 11.7 & 13.3 & 24.5 & 21.3 & 814079 & 948960 \\
\hline $\begin{array}{l}\text { Norfolk-Virginia Beach-Newport News, } \\
\text { VA }\end{array}$ & 11.3 & 13.0 & 22.7 & 18.8 & 277854 & 552493 \\
\hline Odessa, TX & 11.8 & 12.0 & 21.9 & 18.7 & 59032 & 101496 \\
\hline Oklahoma City, OK & 12.3 & 13.2 & 21.5 & 18.4 & 245768 & 423628 \\
\hline Omaha, NE-IA & 12.2 & 13.3 & 21.7 & 18.8 & 214619 & 340565 \\
\hline Orlando, FL & 11.7 & 13.1 & 22.5 & 18.7 & 154095 & 598302 \\
\hline Oxnard-Ventura, CA & 12.1 & 13.3 & 21.6 & 18.5 & 83511 & 259407 \\
\hline Pensacola, FL & 11.5 & 12.8 & 22.9 & 20.1 & 175921 & 307537 \\
\hline Peoria, IL & 11.8 & 13.0 & 23.3 & 19.3 & 131764 & 159114 \\
\hline Philadelphia, PA-NJ & 11.7 & 13.3 & 24.0 & 19.9 & 1782621 & 2268610 \\
\hline Phoenix, AZ & 12.3 & 13.2 & 21.3 & 18.5 & 339996 & 1048770 \\
\hline Pittsburgh, PA & 11.8 & 13.3 & 24.6 & 19.9 & 835990 & 956984 \\
\hline Portland, OR & 12.5 & 13.4 & 22.2 & 18.5 & 359393 & 683078 \\
\hline Providence, RI & 11.2 & 13.1 & 24.8 & 18.4 & 14104 & 17932 \\
\hline Raleigh-Durham, NC & 11.9 & 14.0 & 20.8 & 17.5 & 166559 & 410551 \\
\hline Reading, PA & 11.0 & 12.6 & 24.7 & 20.0 & 125883 & 162847 \\
\hline
\end{tabular}




\begin{tabular}{|c|c|c|c|c|c|c|}
\hline \multirow[t]{2}{*}{ City Name } & \multicolumn{2}{|c|}{$\begin{array}{l}\text { Average } \\
\text { Years of } \\
\text { Schooling }\end{array}$} & \multicolumn{2}{|c|}{\begin{tabular}{|l} 
Average \\
Years of \\
Experience
\end{tabular}} & \multicolumn{2}{|c|}{$\begin{array}{l}\text { Total Private, Non- } \\
\text { Agricultural } \\
\text { Employment }\end{array}$} \\
\hline & '70 & 690 & 670 & '90 & $\cdot 70$ & '90 \\
\hline Reno, NY & 12.5 & 13.1 & 21.9 & 19.5 & 56132 & 151804 \\
\hline Richmond-Petersburg, VA & 11.4 & 13.2 & 22.9 & 18.7 & 265752 & 461658 \\
\hline Riverside-San Bernardino, CA & 12.0 & 12.5 & 22.7 & 18.4 & 282666 & 774484 \\
\hline Roanoke, VA & 11.6 & 12.6 & 23.0 & 21.0 & 86656 & 135770 \\
\hline Rochester, NY & 12.1 & 13.5 & 22.7 & 18.8 & 355418 & 500441 \\
\hline Rockford, IL & 11.4 & 12.7 & 23.3 & 19.9 & 111209 & 150339 \\
\hline Sacramento, CA & 12.6 & 13.4 & 22.2 & 18.5 & 211398 & 594227 \\
\hline Saginaw-Bay City-Midland, MI & 11.6 & 13.0 & 22.4 & 20.5 & 127609 & 167441 \\
\hline St. Louis, MO-IL & 11.6 & 13.1 & 23.8 & 19.3 & 903707 & 1249521 \\
\hline Salem, OR & 12.4 & 12.8 & 22.8 & 19.1 & 48702 & 101563 \\
\hline Salinas-Seaside-Monterey, CA & 12.0 & 12.7 & 22.1 & 20.2 & 61677 & 139790 \\
\hline Salt Lake City-Ogden, UT & 12.8 & 13.4 & 21.3 & 17.5 & 253032 & 575744 \\
\hline San Antonio, TX & 11.1 & 12.8 & 22.6 & 18.6 & 244385 & 498204 \\
\hline San Diego, CA & 12.7 & 13.3 & 21.7 & 17.2 & 363752 & 1061203 \\
\hline San Francisco, CA & 12.7 & 13.8 & 22.2 & 19.0 & 1191491 & 2030555 \\
\hline San Jose, CA & 12.9 & 13.6 & 19.7 & 17.7 & 373632 & 910406 \\
\hline $\begin{array}{l}\text { Santa Barbara-Santa Maria-Lompoc, } \\
\text { CA }\end{array}$ & 12.8 & 13.1 & 21.5 & 19.0 & 78815 & 172008 \\
\hline Santa Rosa-Petaluma, CA & 12.5 & 13.4 & 22.4 & 19.1 & 51310 & 169499 \\
\hline Seattle, WA & 12.7 & 13.6 & 21.2 & 18.5 & 509810 & 1169623 \\
\hline Shreveport, LA & 11.5 & 13.0 & 23.9 & 20.1 & 96858 & 135989 \\
\hline South Bend-Mishawaka, IN & 11.6 & 12.9 & 24.5 & 18.5 & 91007 & 123928 \\
\hline Spokane, WA & 12.6 & 13.4 & 22.7 & 17.1 & 91290 & 159042 \\
\hline Springfield, MO & 12.0 & 12.9 & 21.0 & 17.0 & 67234 & 135646 \\
\hline Springfield, MA & 11.4 & 12.6 & 24.8 & 18.8 & 39372 & 73488 \\
\hline Stockton, CA & 11.7 & 12.4 & 24.3 & 19.7 & 83178 & 165017 \\
\hline Syracuse, NY & 12.2 & 13.4 & 23.3 & 17.9 & 212629 & 316047 \\
\hline Tacoma, WA & 12.1 & 13.1 & 23.5 & 18.6 & 98195 & 196004 \\
\hline $\begin{array}{l}\text { Tampa-St. Petersburg-Clearwater, } \\
\text { FL }\end{array}$ & 11.8 & 13.0 & 23.9 & 20.3 & 353339 & 964453 \\
\hline Terre Haute, IN & 11.8 & 12.9 & 24.2 & 19.1 & 47586 & 56424 \\
\hline Toledo, $\mathrm{OH}$ & 11.8 & 13.0 & 23.0 & 18.5 & 232895 & 291353 \\
\hline Trenton, NJ & 11.7 & 13.6 & 24.0 & 20.2 & 120430 & 165416 \\
\hline Tucson, AZ & 12.3 & 13.2 & 22.9 & 17.6 & 102945 & 256183 \\
\hline Tulsa, OK & 12.0 & 13.2 & 21.8 & 18.7 & 199945 & 354355 \\
\hline Tuscaloosa, AL & 12.0 & 13.0 & 21.1 & 16.3 & 31720 & 55412 \\
\hline Tyler, TX & 11.5 & 12.9 & 25.1 & 20.6 & 38249 & 71843 \\
\hline Utica-Rome, NY & 11.7 & 13.1 & 24.9 & 19.8 & 102463 & 118367 \\
\hline Vallejo-Fairfield-Napa, CA & 12.2 & 13.1 & 23.8 & 19.8 & 49785 & 137181 \\
\hline Waco, TX & 11.3 & 12.5 & 25.2 & 20.6 & 52641 & 80474 \\
\hline Washington, DC-MD-VA & 12.8 & 14.0 & 20.5 & 18.0 & 930498 & 2046568 \\
\hline Waterloo-Cedar Falls, IA & 12.2 & 13.2 & 22.4 & 18.2 & 56209 & 68731 \\
\hline $\begin{array}{l}\text { West Palm Beach-Boca Raton-D. Beach, } \\
\text { FL }\end{array}$ & 11.6 & 12.9 & 24.7 & 21.1 & 129228 & 422008 \\
\hline
\end{tabular}




\begin{tabular}{|l|l|l|l|l|l|l|}
\hline City Name & \multicolumn{2}{|l|}{$\begin{array}{l}\text { Average } \\
\text { Years of } \\
\text { Schooling }\end{array}$} & \multicolumn{2}{|l|}{$\begin{array}{l}\text { Average } \\
\text { Years of } \\
\text { Experience }\end{array}$} & \multicolumn{2}{|l|}{$\begin{array}{l}\text { Total Private, Non- } \\
\text { Agricultural } \\
\text { Employment }\end{array}$} \\
\hline & 770 & $' 90$ & 70 & $' 90$ & 770 & $' 90$ \\
\hline Wichita, KS & 12.3 & 13.1 & 22.6 & 19.7 & 156370 & 261496 \\
\hline Wilmington, DE-NJ-MD & 12.0 & 13.4 & 22.2 & 19.7 & 190549 & 303117 \\
\hline Wilmington, NC & 11.4 & 13.0 & 22.1 & 18.6 & 35038 & 64160 \\
\hline Worcester, MA & 11.5 & 13.2 & 26.3 & 18.7 & 49470 & 84359 \\
\hline York, PA & 11.0 & 12.5 & 24.8 & 19.2 & 137163 & 194569 \\
\hline Youngstown-Warren, OH & 11.8 & 12.7 & 23.9 & 20.9 & 198600 & 207001 \\
\hline
\end{tabular}

\section{A4 Extending the Model to Physical Capital and Land}

Suppose that the aggregate production function is

$$
Y_{c t}=\left(K_{c t}^{\alpha}\left(\Omega_{c t} G\left(L_{c t}, \Lambda_{c t} H_{c t}\right)\right)^{1-\alpha}\right)^{1-\beta} N_{c}^{\beta}, \alpha, \beta \in(0,1)
$$

where $K_{c t}, N_{c}$ denote the amount of physical capital and the fixed amount of land employed in production. Assume that physical capital moves across cities to equalize its rate of return. Then city-year specific competitive equilibrium prices of labor and human capital are

$$
\begin{gathered}
w_{c t}^{L}=(1-\alpha)(1-\beta) \phi\left(r_{t}\right) \Omega_{c t}\left(N_{c} /\left(\Omega_{c t} G\left(L_{c t}, \Lambda_{c t} H_{c t}\right)\right)\right)^{\beta /(1-\alpha(1-\beta))} G_{1}\left(1, \Lambda_{c t} h_{c t}\right) \\
w_{c t}^{H}=(1-\alpha)(1-\beta) \phi\left(r_{t}\right) \Omega_{c t} \Lambda_{c t}\left(N_{c} /\left(\Omega_{c t} G\left(L_{c t}, \Lambda_{c t} H_{c t}\right)\right)\right)^{\beta /(1-\alpha(1-\beta))} G_{2}\left(1, \Lambda_{c t} h_{c t}\right),
\end{gathered}
$$

where $r_{t}$ is the national rate of return to physical capital and $\phi(\bullet)$ some unimportant function. Average labor productivity and the equilibrium average wage satisfy

$$
\begin{aligned}
w_{c t} & =(1-\alpha)(1-\beta)\left(Y_{c t} / L_{c t}\right) \\
& =(1-\alpha)(1-\beta) \phi\left(r_{t}\right) \Omega_{c t}\left(N_{c} /\left(\Omega_{c t} G\left(L_{c t}, \Lambda_{c t} H_{c t}\right)\right)\right)^{\beta /(1-\alpha(1-\beta))} G\left(1, \Lambda_{c t} h_{c t}\right)
\end{aligned}
$$

It is straightforward to show that (A2)-(A4) imply that (19) and (21) become

$$
\begin{gathered}
\lambda \varepsilon^{H}+(1-\lambda) \varepsilon^{L}=\theta-\beta \lambda /(1-\alpha(1-\beta)) \\
\varepsilon-\lambda=\theta-\beta \lambda /(1-\alpha(1-\beta)) .
\end{gathered}
$$

Thus, $\lambda \varepsilon^{H}+(1-\lambda) \varepsilon^{L}$ and $\varepsilon-\lambda$ identify the strength of human capital externalities net of the congestion effect $\beta \lambda /(1-\alpha(1-\beta))$. It is useful to get a sense of the magnitude of this congestion effect. Perfect competition implies that $\beta$ is equal to the share of land in total income, $\alpha$ equal to the share of physical capital in income going to labor and capital, and $\lambda$ equal to the share of human capital in wages. The share of land in total income can be estimated from the Flow of Funds Accounts of the United States, 1982-1990. Estimates for the private economy excluding agriculture and mining are just below 0.01. Combining this estimate with a share of capital in income of 0.3 , and a share of human capital in wages of 0.65 (estimated in the main text), yields an estimate of the congestion effect $\beta \lambda /(1-\alpha(1-\beta)$ ) just below 1 percent. 
The model with physical capital can be extended further by allowing for physical capital externalities in cities following Romer (1986). In this case, however, physical and human capital externalities cannot be identified separately. It is only possible to identify the effect of average human capital on TFP, whether this effect arises directly because of the increase in average human capital or indirectly through the induced increase in physical capital.

\section{A5 Extending the Model to Non-Tradable Goods}

Suppose that the production function is $Y_{c t}=\left(\Omega_{c t} G\left(L_{y c t}, H_{y c t}\right)\right)^{1-\beta} N_{y c t}^{\beta}, \quad \beta \in[0,1)$ for the tradable composite good and $X_{c t}=\left(\Omega_{x c t} G\left(L_{x c t}, H_{x c t}\right)\right)^{1-\beta} N_{x c t}^{\beta}$ for the non-tradable composite good; $N_{y}, N_{x}$ denote the amount of land used in the production of the tradable and nontradable good respectively. Hence, the production functions are identical except that TFP in the production of the non-tradable good may differ from TFP in the production of the tradable good. Suppose also that both goods are produced under perfect competition and that the tradable good is the numeraire. The equilibrium wage schedule in this case is $w_{c t}(H)=w_{c t}^{L}+w_{c t}^{H} H$ and prices of labor and human capital satisfy

$$
\begin{gathered}
w_{c t}^{L}=(1-\beta) \Omega_{c t}^{1-\beta} G\left(1, h_{y c t}\right)^{-\beta}\left(N_{y c t} / L_{y c t}\right)^{\beta} G_{1}\left(1, h_{y c t}\right) \\
w_{c t}^{H}=(1-\beta) \Omega_{c t}^{1-\beta} G\left(1, h_{y c t}\right)^{-\beta}\left(N_{y c t} / L_{y c t}\right)^{\beta} G_{2}\left(1, h_{y c t}\right) .
\end{gathered}
$$

The fact that producers of the non-tradable and the tradable good in each city face the same factor prices implies $h_{y c t}=h_{x c t}=h_{c t}$ and $N_{y c t} / L_{y c t}=N_{x c t} / L_{x c t}=N_{c} / L_{c t}$ where $N_{c}$ is the fixed amount of land available in each city. Hence, prices of labor and human capital in each city satisfy

$$
\begin{gathered}
w_{c t}^{L}=(1-\beta) \Omega_{c t}^{1-\beta} G\left(1, h_{c t}\right)^{-\beta}\left(N_{c} / L_{c t}\right)^{\beta} G_{1}\left(1, h_{c t}\right) \\
w_{c t}^{H}=(1-\beta) \Omega_{c t}^{1-\beta} G\left(1, h_{c t}\right)^{-\beta}\left(N_{c} / L_{c t}\right)^{\beta} G_{2}\left(1, h_{c t}\right) .
\end{gathered}
$$

The approach in Appendix A4 can therefore be used to identify externalities net of congestion effects in the production of the tradable good. A similar analysis applies when only the nontradable good uses land in production.

\section{A6 Extending the Model to Non-Tradable Intermediate Inputs Produced with Increasing Returns to Scale}

The model in the main text concentrates on technological externalities. We now develop a model with an endogenous variety of non-tradable intermediate inputs produced with increasing returns to scale and "pecuniary" instead of technological externalities. Suppose that perfectly competitive firms produce a tradable good according to

$$
Y=F\left(S_{y}, G\left(L_{y}, H_{y}\right)\right)
$$

where both $F(\bullet)$ and $G(\bullet)$ are subject to constant returns to scale and $S$ is a non-tradable intermediate-input composite. Time-subscripts are suppressed throughout. The intermediateinput composite is produced according to

$$
S=\left(\int_{0}^{n} s_{i}^{(\sigma-1) / \sigma} d i\right)^{\sigma /(\sigma-1)}, \sigma>1
$$


where $s_{i}$ is the amount of non-tradable intermediate input $i$ used and $n$ the variety of intermediate inputs available in the city. Non-tradable intermediate inputs are produced in a monopolistically competitive sector according to

$$
s_{i}=\operatorname{Max}\left[F\left(S_{i}, G\left(L_{i}, H_{i}\right)\right)-\kappa, 0\right],
$$

where $S_{i}, L_{i}, H_{i}$ denote intermediate-input composites, labor, and human capital used in the production of intermediate input $i ; \kappa$ is the overhead resource-requirement of production. Each intermediate input is produced by a different firm and there is free entry of firms into the intermediate-inputs sector. It can be shown that the equilibrium wage-schedule of this model is

where

$$
w(H)=w_{c}^{L}+w_{c}^{H} H
$$

$$
\begin{aligned}
& w_{c}^{L}=d\left(L_{c}, h_{c}\right) G_{1}\left(1, h_{c}\right), \\
& w_{c}^{H}=d\left(L_{c}, h_{c}\right) G_{2}\left(1, h_{c}\right),
\end{aligned}
$$

with $L_{c}$ aggregate employment and $h_{c}$ average human capital in the city. Furthermore, average wages are equal to

$$
w_{c}=d\left(L_{c}, h_{c}\right) G\left(1, h_{c}\right) \text {. }
$$

The function $d(L, h)$ is increasing in both arguments and captures the effect of aggregate employment and average human capital in cities on the equilibrium variety of specialized inputs and hence aggregate productivity. It can be seen by comparing (A15)-(A17) with (4)-(6) in the main text that (11), (19), and (21) can be used to identify the elasticity of $d\left(L_{c}, h_{c}\right)$ with respect to aggregate employment and average human capital.

\section{A7 Effects of Labor Supply on Relative Wages}

Define $g\left(\Lambda_{c} h_{c}\right) \equiv G\left(1, \Lambda_{c} h_{c}\right)$. In this case (3)-(5) in the main text yield $w(H)=\Omega_{c} g\left(\Lambda_{c} h_{c}\right)$ $+\Omega_{c} \Lambda_{c} g^{\prime}\left(\Lambda_{c} h_{c}\right)\left(H-h_{c}\right)$. Hence,

$$
\partial \frac{w\left(H_{l}\right)}{w\left(H_{h}\right)} / \partial h_{c}=\frac{g\left(\Lambda_{c} h_{c}\right) \Lambda_{c}^{2} g^{\prime \prime}\left(\Lambda_{c} h_{c}\right)\left(H_{l}-H_{h}\right)}{\left(g\left(\Lambda_{c} h_{c}\right)+\Lambda_{c} g^{\prime}\left(\Lambda_{c} h_{c}\right)\left(H_{h}-h_{c}\right)\right)^{2}}
$$

and

$$
\partial \frac{w\left(H_{l}\right)}{w\left(H_{h}\right)} /\left.\partial L_{c}\left(H_{l}\right)\right|_{L_{c}\left(H_{l}\right)+L_{c}\left(H_{h}\right)=\text { constant }} \frac{g\left(\Lambda_{c} h_{c}\right) \Lambda_{c}^{2} g^{\prime \prime}\left(\Lambda_{c} h_{c}\right)\left(H_{l}-H_{h}\right)^{2}}{\left.L_{c}\left(\Lambda_{c} h_{c}\right)+\Lambda_{c} g^{\prime}\left(\Lambda_{c} h_{c}\right)\left(H_{h}-h_{c}\right)\right)^{2}},
$$

where $g^{\prime \prime}\left(\Lambda_{c} h_{c}\right)=G_{22}\left(1, \Lambda_{c} h_{c}\right)$. The increase in the relative wage of low human capital workers is therefore proportional to $-G_{22}\left(1, \Lambda_{c} h_{c}\right)\left(H_{l}-H_{h}\right)^{2}$ when the supply of low human capital workers decreases and the supply of high human capital workers increases by the same amount. 
